\title{
High-resolution interpolar difference of atmospheric methane around the Last Glacial Maximum
}

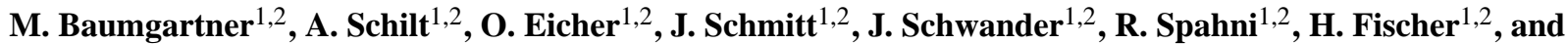 \\ T. F. Stocker ${ }^{1,2}$ \\ ${ }^{1}$ Climate and Environmental Physics, Physics Institute, University of Bern, Sidlerstrasse 5, 3012 Bern, Switzerland \\ ${ }^{2}$ Oeschger Centre for Climate Change Research, University of Bern, 3012 Bern, Switzerland
}

Correspondence to: M. Baumgartner (baumgartner@climate.unibe.ch)

Received: 16 April 2012 - Published in Biogeosciences Discuss.: 9 May 2012

Revised: 28 August 2012 - Accepted: 14 September 2012 - Published: 16 October 2012

\begin{abstract}
Reconstructions of past atmospheric methane concentrations are available from ice cores from both Greenland and Antarctica. The difference observed between the two polar methane concentration levels represents a valuable constraint on the geographical location of the methane sources. Here we present new high-resolution methane records from the North Greenland Ice Core Project (NGRIP) and the European Project for Ice Coring in Antarctica (EPICA) Dronning Maud Land (EDML) ice cores covering Termination 1, the Last Glacial Maximum, and parts of the last glacial back to 32000 years before present. Due to the high resolution of the records, the synchronisation between the ice cores from NGRIP and EDML is considerably improved, and the interpolar concentration difference of methane is determined with unprecedented precision and temporal resolution. Relative to the mean methane concentration, we find a rather stable positive relative interpolar difference throughout the record with its minimum value of $3.7 \pm 0.7 \%$ between 21900 21200 years before present, which is higher than previously estimated in this interval close to the Last Glacial Maximum. This implies that Northern Hemisphere boreal wetland sources were never completely shut off during the peak glacial, as suggested from previous bipolar methane concentration records. Starting at 21000 years before present, i.e. several millennia prior to the transition into the Holocene, the relative interpolar difference becomes even more positive and stays at a fairly stable level of $6.5 \pm 0.8 \%$ during Termination 1 . We thus find that the boreal and tropical methane sources increased by approximately the same factor during Termination 1 . We hypothesise that latitudinal shifts in the Intertropical Convergence Zone (ITCZ) and the monsoon system contribute, either by dislocation of the methane
\end{abstract}

source regions or, in case of the ITCZ, also by changing the relative atmospheric volumes of the Northern and Southern Hemispheres, to the subtle variations in the relative interpolar concentration difference on glacial/interglacial as well as on millennial time scales.

\section{Introduction}

Methane $\left(\mathrm{CH}_{4}\right)$ is a trace gas with a global mean atmospheric concentration of about 1800 parts per billion by volume (ppbv) today and contributed to the greenhouse effect with a radiative forcing (relative to $1750 \mathrm{AD}$ ) of $0.5 \mathrm{~W} \mathrm{~m}^{-2}$ in 2010 (Dlugokencky et al., 2011). The higher $\mathrm{CH}_{4}$ emissions in the Northern Hemisphere compared to the Southern Hemisphere induce an interpolar concentration difference (IPD) which today is (under the anthropogenic influence) about $134 \pm 7 \mathrm{ppbv}(7.6 \pm 0.5 \%)$ averaged over the years from 1985 to 2010 (Dlugokencky et al., 2011), where the uncertainty is the $1 \sigma$ standard deviation over the selected time span. Knowledge of the past latitudinal source distribution is valuable to understand the biogeochemical and climatic changes occurring in glacials, interglacials, and during rapid climate changes such as Dansgaard/Oeschger (DO) events. As the main control of the past IPD, we consider the latitudinal distribution of emissions from boreal and tropical wetlands, which contribute $60-80 \%$ to the total natural source today (Denman et al., 2007). A recent modelling study (Weber et al., 2010) estimates a 4-18\% smaller wetland area and a 35-42\% lower wetland $\mathrm{CH}_{4}$ flux during the Last Glacial Maximum (LGM) compared to the preindustrial Holocene. Wetland $\mathrm{CH}_{4}$ productivity depends 
on temperature, precipitation, and availability of organic material. Recent satellite observations show that temperature is the more critical factor in high northern latitudes and water table depth more dominant in the tropics (Bloom et al., 2010). Changes in the latitudinal distribution of temperature and consequent changes in the latitudinal distribution of precipitation might have regulated changes in the wetland source distribution in the past.

The atmospheric concentration of $\mathrm{CH}_{4}$ is not only influenced by the sources, but also by the sinks. The major sink is the oxidation in the troposphere by the hydroxyl radical $(\mathrm{OH})$, which has its maximum abundance in the tropics (Hein et al., 1997). $\mathrm{CH}_{4}$ has a mean atmospheric lifetime of $8.7 \pm 1.3$ years today (Denman et al., 2007). The influence on the atmospheric lifetime of $\mathrm{CH}_{4}$ of sink competitors such as biogenic volatile organic compounds (BVOC) is still debated. While Kaplan et al. (2006) invoke major changes in the atmospheric lifetime due to large changes in the BVOC emissions over Termination 1, Levine et al. (2011) find the effect of changes in BVOC emission to be compensated by the effects of changes in air temperatures on humidities and gas-phase chemical kinetics. Levine et al. (2012) confirm this statement also for DO events, and suggest that the changes in $\mathrm{CH}_{4}$ are mainly source driven.

Ice cores from Greenland and Antarctica allow us to reconstruct past atmospheric $\mathrm{CH}_{4}$ variations and hence to constrain the latitudinal source distribution by the knowledge of the IPD (Brook et al., 2000; Chappellaz et al., 1997; Dällenbach et al., 2000). In this study, we measure the $\mathrm{CH}_{4}$ concentration along the NGRIP (Greenland) and EDML (Antarctica) ice cores. In two-box and three-box model simulations, the measured concentrations are used as inputs to estimate the source strengths in both the Northern and Southern Hemisphere. Finally, we discuss the processes which might have caused the observed changes in the past source distribution.

\section{New data}

Figure 1 presents the two new high-resolution atmospheric $\mathrm{CH}_{4}$ records measured along the NGRIP (blue, 469 new measurements) and EDML (red, 190 new measurements) ice cores covering the time interval between 32 and 11 thousand years before present (kyr BP) on the unified EDML gas age scale derived by Lemieux-Dudon et al. (2010). This includes the Younger Dryas (YD), the Bølling/Allerød (BA), the LGM and the response to the DO events 2, 3, and 4. Earlier published EDML data (EPICA Community Members, 2006) are included in our calculations, where 83 remeasurements show a mean difference of $0.3 \mathrm{ppbv}$ and a standard deviation of $13.9 \mathrm{ppbv}$. A few NGRIP data points published earlier (Schilt et al., 2010b) are included as well. The mean time resolution is $43 \mathrm{yr}$ for NGRIP and $59 \mathrm{yr}$ for EDML on the unified EDML gas age scale. This is in the order of the width of the gas age distributions of the enclosed air from NGRIP and EDML. Details about the measurement system are described in Sect. 2.3.

\subsection{Synchronisation}

Precise synchronisation between the ice cores from Greenland and Antarctica is a prerequisite to calculate the IPD of $\mathrm{CH}_{4}$. The fast and strong variations in the greenhouse gas $\mathrm{CH}_{4}$ can be used to synchronise the gas ages from different ice cores (Blunier et al., 2007). Ironically, the existence of the IPD, which we want to calculate based on a precise synchronisation, renders the latter difficult, since for every tie point we assume a certain IPD value (e.g. Buiron et al., 2011). Based on the assumption that fast $\mathrm{CH}_{4}$ variations occur simultaneously in both hemispheres, our new highresolution data improve the synchronisation of the NGRIP and EDML gas records. Particularly, a new tie point is defined at $20.9 \mathrm{kyrBP}$, and the uncertainty of the tie points at the start and the end of DO event 2 is substantially reduced. We use $29 \mathrm{CH}_{4}$ tie points (Table A1, black triangles on top of Fig. 1) to improve the synchronisation of the NGRIP $\mathrm{CH}_{4}$ record to the unified EDML gas age scale derived by Lemieux-Dudon et al. (2010). The start of the slow $\mathrm{CH}_{4}$ increase at $18 \mathrm{kyr} \mathrm{BP}$ is also used as a tie point, assuming constant increase rates in both hemispheres. This assumption is not necessarily true, since the IPD represents an additional degree of freedom and induces a substantial synchronisation uncertainty in this case. We thus apply a synchronisation uncertainty of this tie point of $500 \mathrm{yr}$, which is much larger than that of rapid $\mathrm{CH}_{4}$ changes $(\approx 50 \mathrm{yr})$.

\subsection{Gravitational fractionation}

In the context of the calculation of the IPD, we have to discuss the gravitational fractionation in the firn column which decreases the $\mathrm{CH}_{4}$ concentration at the close-off depth compared to the atmospheric value. The gravitational depletion in the considered time interval is relatively stable with mean values of $2.9 \pm 0.6 \mathrm{ppbv}$ for NGRIP and $2.4 \pm 0.4 \mathrm{ppbv}$ for EDML, where the close-off depth was calculated using the densification model by Herron and Langway (1980) with an estimated temperature and accumulation rate history from NGRIP (Johnsen et al., 2001; NGRIP Project Members, 2004) and EDML (Ruth et al., 2007; EPICA Community Members, 2006). The atmospheric IPD would thus be about $0.5 \pm 0.7 \mathrm{ppbv}$ higher than the IPD measured in the ice cores. The effect on the relative interpolar difference (rIPD) is less than $0.1 \%$, which is small compared to the overall error. Thus, we do not correct the data for gravitational depletion, in line with previous ice core studies (e.g. Buiron et al., 2011; Stenni et al., 2011; Schilt et al., 2010a,b; EPICA Community Members, 2006; Huber et al., 2006; Spahni et al., 2005; Flückiger et al., 2004). 


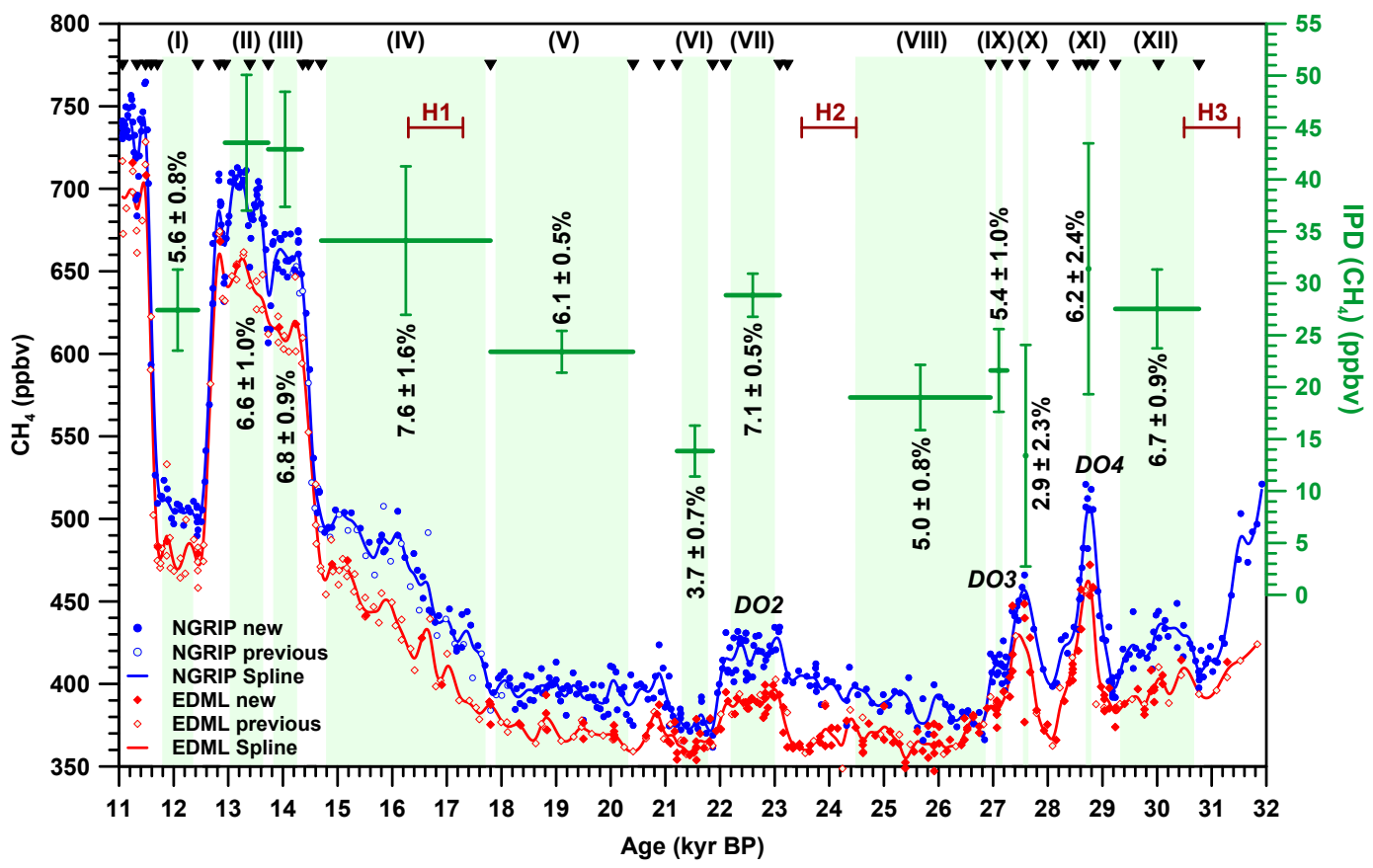

Fig. 1. Atmospheric $\mathrm{CH}_{4}$ concentration between 32 and $11 \mathrm{kyr} \mathrm{BP}$ reconstructed from polar ice core measurements. Data from Greenland (NGRIP) are plotted as blue circles and data from Antarctica (EDML) as red diamonds. Earlier published data (NGRIP from Schilt et al. (2010a) and EDML from EPICA Community Members, 2006) are shown as open symbols. The splines through the data are calculated according to Enting (1987) with a cutoff period of $350 \mathrm{yr}$. Mean IPD values (Table 1) are in green, where the horizontal bar and the green shaded area indicate the time interval and the vertical error bar shows the standard error of the mean. Corresponding relative interpolar difference (rIPD) values are indicated as black numbers. Heinrich Events (H) 1 to 3 (Hemming, 2004) are indicated in brown. Tie points for synchronisation (Sect. 2.1) are indicated on the top as black triangles. All $\mathrm{CH}_{4}$ concentrations are synchronised to the unified EDML gas age scale derived by Lemieux-Dudon et al. (2010).

\subsection{Measurement system}

We use a wet extraction technique according to Chappellaz et al. (1997) and Flückiger et al. (2004) to separate the enclosed air from the surrounding ice (sample size $40 \mathrm{~g}$, corresponds to a depth interval of 3 and $5 \mathrm{~cm}$, for EDML and NGRIP, respectively). In brief, a sample is put in a small glass container and after evacuation of the ambient air, the ice is melted in a heat bath $\left(50^{\circ} \mathrm{C}\right)$ and refrozen from bottom to top on a cooling plate $\left(-40^{\circ} \mathrm{C}\right)$. The headspace volume is expanded into an evacuated and temperaturecontrolled $\left(-60^{\circ} \mathrm{C}\right)$ sampling loop and analysed by gas chromatography using a thermal conductivity detector (TCD) $\left(\mathrm{N}_{2}+\mathrm{O}_{2}+\mathrm{Ar}\right)$ and a flame ionisation detector (FID) $\left(\mathrm{CH}_{4}\right)$. Two standard gases $\left(\mathrm{CH}_{4}\right.$ concentration at $408 \mathrm{ppbv}$ and $1050 \mathrm{ppbv}$ ) are used to calibrate the detectors at hourly intervals. Each calibration is checked by a control measurement with a third standard gas showing a mean concentration of $529.4 \pm 3.1 \mathrm{ppbv}$ over the entire measurement series. Intercalibration measurements with NOAA standard gases show that the Bern $\mathrm{CH}_{4}$ concentrations are about $1 \%$ higher compared to measurements performed on the NOAA scale. The reproducibility of measurements on natural ice samples was further determined by the analysis of a series of 5 adjacent samples in 18 depth intervals. 83 data points show a precision of $6.2 \mathrm{ppbv}$, where 7 points have been rejected because of too high values caused by badly sealed glass containers (more than $3 \sigma$ higher than the mean of the other reproducibility measurements from the same depth-interval). In contrast to Mitchell et al. (2011), who observe a loss of $\mathrm{CH}_{4}$ due to solubility effects during the wet extraction process, blank measurements with air-free ice and standard gas show a concentration independent contamination (Chappellaz et al., 1997) on the order of $10 \mathrm{ppbv}$, depending on the particular glass container. For each of the glass extraction containers, we determine a separate correction value, which is subtracted from each measurement on natural ice.

\section{Interpolar concentration difference of $\mathrm{CH}_{4}$}

The interpolar concentration difference of $\mathrm{CH}_{4}$ is a valuable constraint on the geographical location of the $\mathrm{CH}_{4}$ sources. For the determination of the IPD of only a few ppbv, we must exclude any systematic offsets between the $\mathrm{CH}_{4}$ records from both polar ice sheets. The sampling and measurement strategy of this study was designed for an optimum determination of the IPD. For the first time, all the new data points are 
analysed in the same laboratory, relative to the same standard gases and within the same year of measurement. On each measurement day we analysed both samples from Greenland and Antarctica. Samples of different ages were measured in randomised order over the complete record to avoid systematic drifts in the IPD. Due to the quasi-simultaneously analysed samples, we are confident of the accuracy of the new IPD values. Note that there are still potential systematic error sources like, for example, in situ production of $\mathrm{CH}_{4}$ by bacteria and/or chemical reactions in any of the ice cores. However, in situ production of $\mathrm{CH}_{4}$ in the dry snow zone of polar ice sheets has not been proven yet.

\subsection{Definition and calculation of IPD and rIPD}

We define the interpolar concentration difference of $\mathrm{CH}_{4}$ in an absolute (IPD) and a relative manner (rIPD) similar to Brook et al. (2000):

$\mathrm{IPD}=c_{\mathrm{n}}-c_{\mathrm{s}}$

and

$\mathrm{rIPD}=\frac{c_{\mathrm{n}}-c_{\mathrm{s}}}{\frac{1}{2}\left(c_{\mathrm{n}}+c_{\mathrm{s}}\right)}=\frac{\mathrm{IPD}}{\frac{1}{2}\left(c_{\mathrm{n}}+c_{\mathrm{s}}\right)}$,

where $c_{\mathrm{n}}$ (index $\mathrm{n}$ : Northern Hemisphere) and $c_{\mathrm{s}}$ (index $\mathrm{s}$ : Southern Hemisphere) represent the concentrations measured along the NGRIP and EDML ice cores, respectively.

As described in Sect. 2.1, the synchronisation uncertainty is relatively small for most of the tie points. However, the $\mathrm{CH}_{4}$ synchronisation provides no information about the timing between the tie points, where linear interpolation must be assumed. Therefore, we calculate $c_{\mathrm{n}}, c_{\mathrm{s}}$, and the IPD as means over specific time intervals instead of a continuous IPD record. By calculating a mean value, and not a timeweighted mean value as in Chappellaz et al. (1997), we essentially assume constant $\mathrm{CH}_{4}$ levels within the intervals, since the mean value over an interval with, for example, two different $\mathrm{CH}_{4}$ levels would only be the same as the timeweighted mean value if the data resolution is exactly constant over the whole time interval.

The uncertainty in the calculated IPD is dependent both on the measurement and the synchronisation error. For the EDML measurement error, we assign the standard error of the mean to the mean value $c_{\mathrm{s}}$ of an interval. For the NGRIP record we basically do the same but use a Monte-Carlo approach to simultaneously estimate the synchronisation error. For a total of $10^{5}$ simulations, we randomly change the NGRIP start and end points of each interval. With the exception of the point at $24.4 \mathrm{kyrBP}$, these start and end points coincide with the tie points. For each simulation, the new NGRIP tie points are chosen randomly and uniformly distributed within the synchronisation uncertainty around the original tie points. Hereby, we assign a slightly different gas age to all NGRIP data points. For each simulation $i=1 \ldots 10^{5}$ and time interval, the mean concentration $c_{\mathrm{n}, i}$ and the standard error $\mathrm{SE}_{i}$ of the mean concentration are calculated. The final mean NGRIP concentration $c_{\mathrm{n}}$ and its measurement error are calculated as the mean of all simulated mean concentrations $c_{\mathrm{n}, i}$ and the mean of all simulated standard errors $\mathrm{SE}_{i}$, respectively. The synchronisation error is calculated as the standard deviation of all mean concentrations $c_{\mathrm{n}, i}$. Errors for the IPD and rIPD are calculated from the standard errors of $c_{\mathrm{n}}, c_{\mathrm{s}}$, and the synchronisation error.

The criterion of constant $\mathrm{CH}_{4}$ levels is not a reasonable assumption for the interval 17.8-14.8 kyrBP, where the $\mathrm{CH}_{4}$ concentrations in both hemispheres show approximately a linear increase. We thus calculate the IPD as the mean difference between two linear fits through the data. In order to account for synchronisation uncertainties, the NGRIP tie points are varied and the error of the IPD is obtained as the standard deviation of all $10^{5}$ simulated IPD values.

Since the DO events 3 and 4 are too short to calculate a mean value over their duration, we estimate the IPD using the maximum atmospheric concentrations observed during the events (for more details see Sect. 3.4).

\subsection{IPD in specified time intervals}

A complete list of specified time intervals (I)-(XII), which correspond to the green shaded areas (plus DO events 3 and 4) in Fig. 1, and associated IPD and rIPD values are given in Table 1. We observe a positive IPD and hence a predominance of northern hemispheric sources compared to southern hemispheric sources throughout the record. Beside the very low IPD value during DO event 3 , which has a large uncertainty, the minimum IPD of $13.8 \pm 2.5 \mathrm{ppbv}$ $(3.7 \pm 0.7 \%)$ is observed just after DO event 2 (interval VI), which is within the time interval of maximum ice sheet extent (Clark et al., 2009). The maximum IPD of $43.5 \pm 6.5 \mathrm{ppbv}$ $(6.6 \pm 1.0 \%)$ is observed during the BA (interval II).

We refrain from calculating the IPD in the time interval 24.4-23.2 kyrBP because the EDML data are inconsistent with the Talos Dome Ice Core Project (TALDICE) data (Buiron et al., 2011; Stenni et al., 2011). This inconsistency is marked as the grey shaded interval in Fig. 2. Before DO event 2, TALDICE (yellow) and NGRIP (blue) show an increase in the $\mathrm{CH}_{4}$ concentration from $26 \mathrm{kyr} B P$ until the onset of DO event 2. This pattern is visible in EDML (red) prior to $24 \mathrm{kyrBP}$; however, just before DO event 2, the concentration level drops suddenly to $365.2 \mathrm{ppbv}$, corresponding to the grey shaded area in Fig. 2. Remeasurements of the EDML samples in this 20 ppbv concentration dip confirm the low concentration level and exclude a problem in the measurement system. With the current time resolution of the TALDICE record, the EDML dip can not be entirely rejected. High-resolution measurements on other Antarctic ice cores will be crucial to resolve this issue. We note that TALDICE 
Table 1. List of time intervals where the IPD is calculated (see also Fig. 1).

\begin{tabular}{|c|c|c|c|c|c|c|c|c|c|c|c|c|c|c|c|c|}
\hline \multicolumn{2}{|c|}{ Interval } & \multirow{2}{*}{$\begin{array}{r}\begin{array}{r}\text { Mean Age } \\
(\mathrm{yr} B P)\end{array} \\
12078\end{array}$} & \multirow{2}{*}{$\begin{array}{r}\begin{array}{r}\text { Duration } \\
(\mathrm{yr})\end{array} \\
742\end{array}$} & \multirow{2}{*}{$\begin{array}{r}\begin{array}{r}\text { NGRIP } \\
\text { (points) }\end{array} \\
21\end{array}$} & \multirow{2}{*}{$\begin{array}{c}\begin{array}{c}\mathrm{CH}_{4} \\
\text { (ppbv) }\end{array} \\
506.9\end{array}$} & \multirow{2}{*}{$\begin{array}{c}\begin{array}{c}\text { Error } \\
\text { (ppbv) }\end{array} \\
1.8\end{array}$} & \multirow{2}{*}{$\begin{array}{r}\begin{array}{r}\text { EDML } \\
\text { (points) }\end{array} \\
22\end{array}$} & \multirow{2}{*}{$\begin{array}{c}\begin{array}{c}\mathrm{CH}_{4} \\
\text { (ppbv) }\end{array} \\
479.5\end{array}$} & \multirow{2}{*}{$\begin{array}{c}\begin{array}{c}\text { Error } \\
\text { (ppbv) }\end{array} \\
3.2\end{array}$} & \multirow{2}{*}{$\begin{array}{c}\begin{array}{c}\text { IPD } \\
\text { (ppbv) }\end{array} \\
27.4\end{array}$} & \multirow{2}{*}{$\begin{array}{r}\begin{array}{r}\text { Error } \\
(\mathrm{ppbv})\end{array} \\
3.9\end{array}$} & \multirow{2}{*}{$\begin{array}{c}\begin{array}{r}\text { rIPD } \\
(\%)\end{array} \\
5.6\end{array}$} & \multirow{2}{*}{$\begin{array}{c}\begin{array}{c}\text { Error } \\
(\%)\end{array} \\
0.8\end{array}$} & \multirow{2}{*}{$\frac{\begin{array}{c}s_{\mathrm{n}} \\
\left(\operatorname{Tg~yr}^{-1}\right)\end{array}}{96}$} & \multirow{2}{*}{$\frac{\begin{array}{c}s_{\mathrm{S}} \\
\left(\mathrm{Tgyr}^{-1}\right)\end{array}}{48}$} & \multirow{2}{*}{$\begin{array}{c}\begin{array}{c}s_{\text {tot }} \\
\left(\operatorname{Tg~yr}^{-1}\right)\end{array} \\
143\end{array}$} \\
\hline (I) & YD & & & & & & & & & & & & & & & \\
\hline (II) & BA1 & 13339 & 792 & 34 & 686.0 & 4.2 & 13 & 642.5 & 4.0 & 43.5 & 6.5 & 6.6 & 1.0 & 135 & 58 & 193 \\
\hline (III) & BA2 & 14044 & 617 & 29 & 655.0 & 3.1 & 11 & 612.1 & 4.3 & 42.9 & 5.5 & 6.8 & 0.9 & 130 & 54 & 184 \\
\hline (IV) & $\mathrm{H} 1$ & 16254 & 3099 & 55 & 463.2 & 1.9 & 39 & 429.1 & 1.6 & 34.1 & 7.1 & 7.6 & 1.6 & 95 & 35 & 130 \\
\hline$(\mathrm{V})^{+}$ & St1 & 19109 & 2611 & 63 & 395.9 & 1.2 & 29 & 372.5 & 1.3 & 23.4 & 2.0 & 6.1 & 0.5 & 77 & 35 & 112 \\
\hline (VI) & LGM & 21545 & 656 & 17 & 376.7 & 1.8 & 20 & 362.8 & 1.5 & 13.8 & 2.5 & 3.7 & 0.7 & 66 & 42 & 108 \\
\hline (VII) & $\mathrm{DO} 2$ & 22605 & 984 & 35 & 419.0 & 1.8 & 28 & 390.2 & 1.1 & 28.9 & 2.1 & 7.1 & 0.5 & 84 & 33 & 118 \\
\hline (VIII) & St2 & 25672 & 2568 & 34 & 387.2 & 2.1 & 49 & 368.2 & 1.4 & 19.0 & 3.1 & 5.0 & 0.8 & 72 & 38 & 110 \\
\hline (IX) & St2 & 27108 & 306 & 14 & 408.3 & 2.9 & 11 & 386.7 & 1.9 & 21.6 & 4.0 & 5.4 & 1.0 & 77 & 39 & 116 \\
\hline$(\mathrm{X})^{\mathrm{o}}$ & DO3 & 27600 & 0 & 1 & 461.5 & 6.7 & 1 & 448.1 & 8.3 & 13.4 & 10.7 & 2.9 & 2.3 & 78 & 54 & 132 \\
\hline$(\mathrm{XI})^{\mathrm{o}}$ & DO4 & 28750 & 0 & 1 & 518.7 & 7.2 & 1 & 487.3 & 9.7 & 31.4 & 12.1 & 6.2 & 2.4 & 101 & 46 & 146 \\
\hline (XII) & St3 & 30005 & 1531 & 32 & 421.9 & 2.4 & 21 & 394.3 & 2.2 & 27.5 & 3.8 & 6.7 & 0.9 & 84 & 35 & 119 \\
\hline
\end{tabular}

* Due to the variation of the NGRIP tie points (Sect. 3.2), this is the mean value of all simulations and might thus not be an integer number.

${ }^{\circ}$ IPD estimate based on one point (maxima of DO event) and after application of the firn model.

+ Used as reference interval in Fig. 7d.

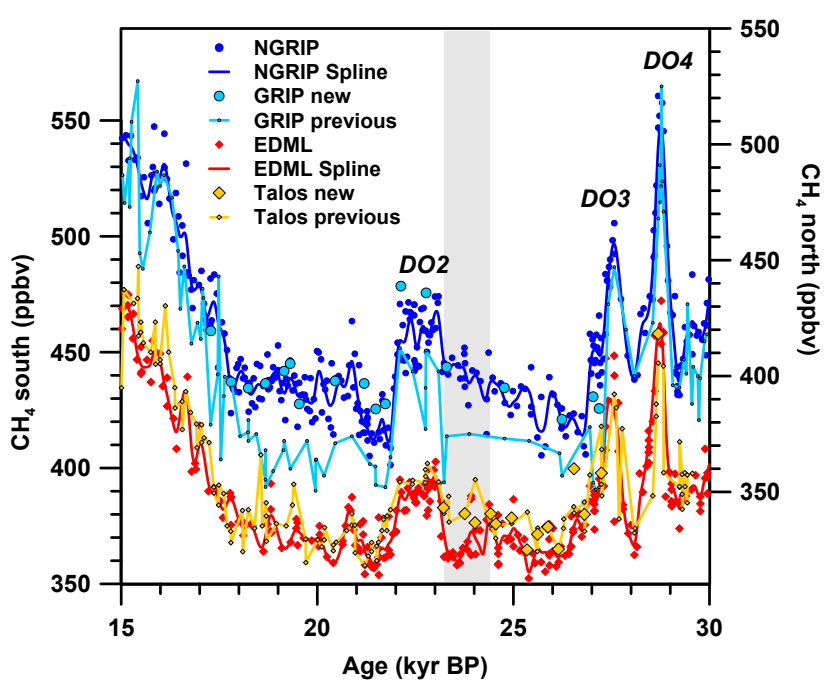

Fig. 2. Remeasurements along the GRIP and TALDICE ice cores. For clarity reasons, data from Greenland (circles) and Antarctica (diamonds) are shown on different concentration axes. The NGRIP (blue, Schilt et al. (2010b) and new data) and EDML (red, EPICA Community Members (2006) and new data) data are the same as in Fig. 1. Additionally plotted are the previous GRIP record (Blunier et al., 1998; Dällenbach et al., 2000) (light blue) and the TALDICE record (Buiron et al., 2011; Stenni et al., 2011) (yellow). New GRIP and TALDICE remeasurements are shown as big light blue and yellow symbols, respectively. The grey shaded area marks the time interval, where the EDML record deviates from the TALDICE record. All $\mathrm{CH}_{4}$ concentrations are synchronised to the unified EDML gas age scale derived by Lemieux-Dudon et al. (2010).

data suggest that the IPD would be similar as in the interval before.

\subsection{Comparison with previous results}

Figure 3 shows a compilation of new and existing (Brook et al., 2000; Chappellaz et al., 1997; Dällenbach et al., 2000)
rIPD values. The new rIPD values between 21.9-17.8 kyr BP are in agreement with Brook et al. (2000) but are significantly larger than the estimate from Dällenbach et al. (2000). This difference results from a concentration offset between our new NGRIP data and the previously measured Greenland Ice Core Project (GRIP) data (Blunier et al., 1998; Dällenbach et al., 2000). Figure 2 shows that the GRIP data (light blue line) tend to be up to $30 \mathrm{ppbv}$ lower than the NGRIP data (blue line) in certain time intervals. The GRIP data especially show a larger bias towards lower concentrations. On the other hand, Antarctic records are consistent with the new EDML data. We remeasured 18 data points (round light blue symbols) along the GRIP ice core and found a good agreement with our new NGRIP concentration level. A contamination of the GRIP ice due to the long storage time and an accompanying gas loss (Bereiter et al., 2009) is unlikely, since we eliminated about $5 \mathrm{~mm}$ of the outer surface when preparing the ice. The reliability among the new data emphasises the importance of measuring both hemispheric records in the same laboratory, with the same extraction technique, and using the same standard gases to correctly determine the IPD.

The rIPD values of the DO events $2(7.1 \pm 0.5 \%)$ and 4 $(6.2 \pm 2.4 \%)$ are well in the range of previous results from Brook et al. (2000) for DO event $8(7.8 \pm 2.0 \%)$ and with the mean value over several DO events $(7.5 \pm 2.1 \%)$ from Dällenbach et al. (2000). The rIPD value for DO event 3 $(2.9 \pm 2.3 \%)$ is lower but has a large uncertainty.

For the BA period, we find a rIPD value twice as large as estimated by Brook et al. (2000) and Dällenbach et al. (2000). For the YD period, the new rIPD value is in agreement with Dällenbach et al. (2000) and 1.5 times larger than the value from Brook et al. (2000).

\subsection{IPD during the DO events 3 and 4}

In contrast to the other parts of the new $\mathrm{CH}_{4}$ record, the DO events 3 and 4 are too short to calculate the IPD as a mean over a specific time interval. Thus, we estimate the 


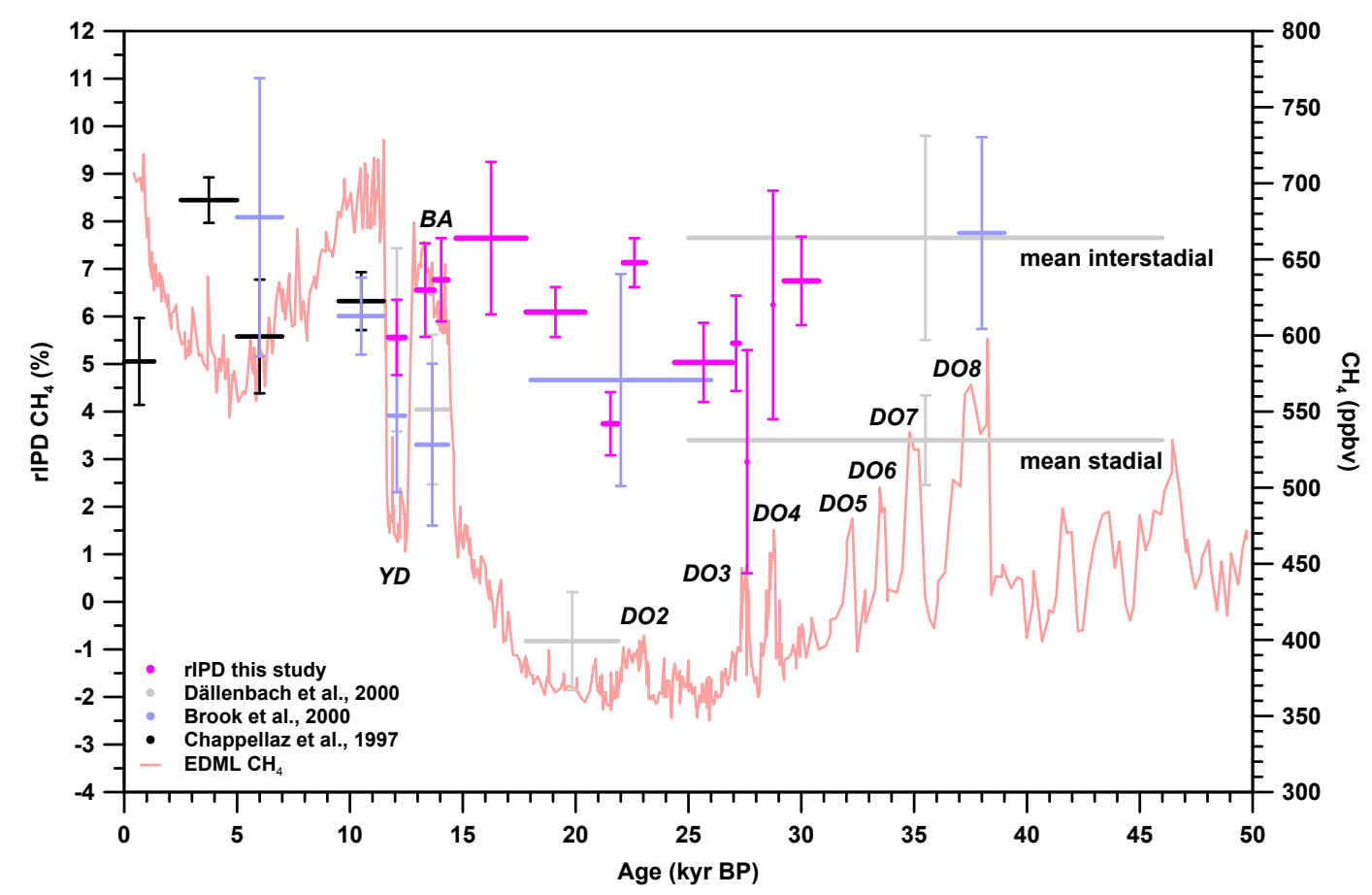

Fig. 3. Compilation of rIPD values for atmospheric $\mathrm{CH}_{4}$ reconstructed from polar ice cores. Values from previous studies are given in black (Chappellaz et al., 1997): based on GRIP, D47 and Byrd; blue (Brook et al., 2000): based on GISP2 and Taylor Dome; and grey (Dällenbach et al., 2000): based on GRIP, Byrd and Vostok. New values, corresponding to the time intervals of Fig. 1 and Table 1, are shown in pink. The $\mathrm{CH}_{4}$ concentration from EDML is plotted in red. All data are synchronised to the unified EDML gas age scale derived by Lemieux-Dudon et al. (2010).

interstadial IPD using an estimate of the maximum atmospheric concentrations observed during the events. However, because such fast and short atmospheric variations are attenuated due to molecular diffusion and gradual bubble close-off in the firn of an ice sheet, we first apply a forward smoothing firn model (Schwander et al., 1993; Spahni et al., 2003) to take into account the different enclosure characteristics of the EDML and the NGRIP sites. Temperature and accumulation rate, which both strongly influence the firn structure, are assumed to be similar at both sites during stadial conditions (NGRIP: $-50.5 \pm 6.6^{\circ} \mathrm{C}, 0.054 \pm 0.020 \mathrm{mH}_{2} \mathrm{Oyr}^{-1}$; EDML: $\left.-51.9 \pm 1.4^{\circ} \mathrm{C}, 0.030 \pm 0.004 \mathrm{~m} \mathrm{H}_{2} \mathrm{Oyr}^{-1}\right)$. During the DO events 3 and 4 , both temperature $\left(-43.6 \pm 4.8^{\circ} \mathrm{C}\right)$ and accumulation rate $\left(0.086 \pm 0.023 \mathrm{~m} \mathrm{H}_{2} \mathrm{Oyr}^{-1}\right)$ jump up to higher values in the NGRIP ice core. The estimates are taken from the ss09sea age scale (Johnsen et al., 2001) based on the $\delta^{18} \mathrm{O}$ reconstructions (NGRIP Project Members, 2004) combined with the temperature- $\delta^{18} \mathrm{O}$ relationship derived from $\delta^{15} \mathrm{~N}$ measurements (Huber et al., 2006). The higher temperature and accumulation rate during the interstadial periods lead to weaker attenuation at NGRIP compared to the EDML site, where we assume a temperature of $-50.2 \pm 1.7^{\circ} \mathrm{C}$ and an accumulation rate of $0.036 \pm 0.006 \mathrm{~m} \mathrm{H}_{2} \mathrm{Oyr}^{-1}$ (EPICA Community Members, 2006; Ruth et al., 2007). Without application of the firn model, the IPD would be overestimated for these two short interstadial periods. Consequently, the in- terstadial rIPD recorded in the ice cores without enclosure correction represents an upper limit, which is $6.3 \%$ for DO event 3 and $9.3 \%$ for DO event 4.

The application of the firn model helps to derive the interstadial IPD for DO event 3 and 4 more precisely. The model needs several input parameters. For the close-off density, the surface density and the tortuosity at NGRIP and EDML, we use the recent values specified by Spahni et al. (2003) for GRIP and EPICA Dome C, respectively. Since we use a forward smoothing model, we first need to estimate the atmospheric signal, which serves as input for the firn model. The atmospheric signal is then attenuated due to molecular diffusion and gradual bubble close-off in the firn (Schwander et al., 1993). The closed-off concentration, which we measure, is different compared to the original atmospheric concentration. Note that the estimation of the atmospheric signal has no unique solution, since mathematically it is a deconvolution. We follow Spahni et al. (2003) and simply linearly scale the $\mathrm{CH}_{4}$ amplitude of the NGRIP signal to construct the estimate of both the northern and southern atmospheric signal.

The constructed northern atmospheric signal is the input for the firn model at the NGRIP site, where we apply three different attenuation scenarios (mean [min,max]; Fig. 4). The smallest root mean square difference between the output of the firn model and the measured NGRIP data is achieved 

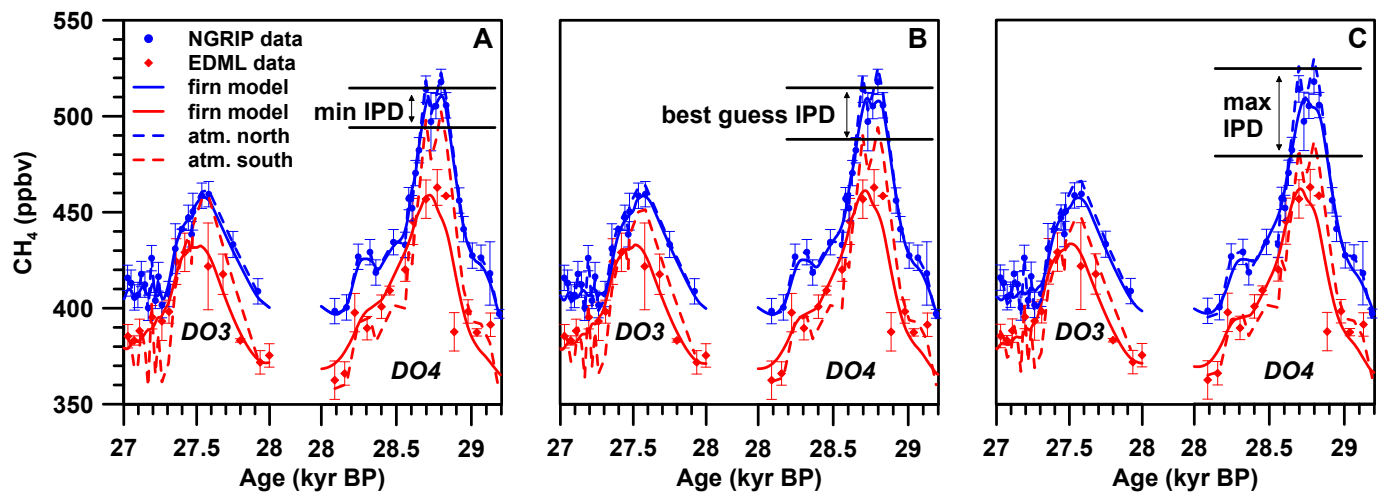

Fig. 4. Firn model applied on DO events 3 and 4. Shown are the NGRIP data (blue circles) and EDML data (red diamonds) corresponding to Fig. 1. Atmospheric signals constructed by linear scaling and shifting the NGRIP data are shown as dotted lines. The corresponding firn model output is shown in blue for NGRIP and in red for EDML. (A) Minimum IPD: minimum attenuation at NGRIP, maximum attenuation at EDML. (B) Mean IPD: mean attenuation at NGRIP, mean attenuation at EDML. (C) Maximum IPD: maximum attenuation at NGRIP, minimum attenuation at EDML.

when the linear scaling factor is $1.13[1.06,1.19]$ for DO event 3 and $1.08[1.05,1.13]$ for DO event 4 . The southern atmospheric signal, which is obtained by linear scaling of the $\mathrm{CH}_{4}$ amplitude of the NGRIP signal as well, is the input for the firn model at the EDML site, where we apply again three different attenuation scenarios. The smallest root mean square difference between the output of the firn model and the measured EDML data is obtained by varying the linear scaling factor $(1.48[1.35,1.62]$ for DO event 3 and $1.11[1.02,1.21]$ for DO event 4$)$ and the offset between the NGRIP and EDML data, which has been assumed to be constant over the entire DO event.

The resulting IPD $(13.4 \pm 10.7 \mathrm{ppbv}$ for DO event 3 and $31.4 \pm 12.1 \mathrm{ppbv}$ for DO event 4 ) is calculated as the difference between the maximum concentrations of the splines (cutoff period $100 \mathrm{yr}$ ) through the atmospheric input signals, where the maximum attenuation at NGRIP is combined with the minimum attenuation at EDML and vice versa. The resulting rIPD is $(2.9 \pm 2.3 \%)$ for DO event 3 and $(6.2 \pm 2.4 \%)$ for DO event 4.

\section{Source distribution of $\mathrm{CH}_{4}$}

The new NGRIP and EDML records provide the concentrations of $\mathrm{CH}_{4}$ in the northern $\left(c_{\mathrm{n}}\right)$ and southern $\left(c_{\mathrm{s}}\right)$ hemispheres. This enables us to formulate a two-box model to estimate the $\mathrm{CH}_{4}$ source strength in the Northern $\left(s_{\mathrm{n}}\right)$ and Southern $\left(s_{\mathrm{s}}\right)$ Hemispheres. In this two-box model, the northern box $\left(0^{\circ} \mathrm{N}-90^{\circ} \mathrm{N}\right.$, index: $\left.\mathrm{n}\right)$ and the southern box $\left(0^{\circ} \mathrm{S}-\right.$ $90^{\circ} \mathrm{S}$, index: s) account for $50 \%$ of the total atmospheric volume each. The mass balance (Tans, 1997) is given by:

$$
\frac{\mathrm{d} \boldsymbol{M}}{\mathrm{d} t}=\boldsymbol{S}-\boldsymbol{\Omega} \cdot \boldsymbol{M}
$$

$\boldsymbol{M}=m^{*} \cdot\left(\begin{array}{c}c_{\mathrm{n}} \\ c_{\mathrm{s}}\end{array}\right), \quad \boldsymbol{S}=\left(\begin{array}{c}s_{\mathrm{n}} \\ s_{\mathrm{s}}\end{array}\right), \quad m^{*}=\frac{m_{0}}{c_{0}} \cdot \frac{V_{\mathrm{hem}}}{V_{\mathrm{atm}}}$

and

$\boldsymbol{\Omega}=\left(\begin{array}{cc}\frac{1}{\tau}+\frac{1}{\tau_{\mathrm{ex}}} & -\frac{1}{\tau_{\mathrm{ex}}} \\ -\frac{1}{\tau_{\mathrm{ex}}} & \frac{1}{\tau}+\frac{1}{\tau_{\mathrm{ex}}}\end{array}\right)$,

where $\boldsymbol{M}$ is a vector of the atmospheric $\mathrm{CH}_{4}$ burden $\left(\operatorname{Tgbox}{ }^{-1}\right)$. The factor $m^{*}$ converts the concentrations (ppbv) into mass ( $\mathrm{Tg}$ ) where we use the relation between a mean atmospheric concentration $c_{0}=1650 \mathrm{ppbv}$ and a corresponding global atmospheric inventory of $m_{0}=4800 \mathrm{Tg}$ from Steele et al. (1992). The volume of one hemisphere $V_{\text {hem }}$ is assumed to be $50 \%$ of the total atmospheric volume $V_{\text {atm }}$, which induces a factor of $\frac{1}{2} . S$ is a vector which summarises the $\mathrm{CH}_{4}$ sources (Tg year ${ }^{-1}$ ), $\boldsymbol{\Omega}$ is the exchange matrix with $\tau$ the atmospheric lifetime of $\mathrm{CH}_{4}$, and $\tau_{\text {ex }}$ the interhemispheric mixing time.

We initialise the model with a present-day source strength $\left(490 \mathrm{Tg} \mathrm{yr}^{-1}\right)$ and a source distribution from Fung et al. (1991) (scenario 7) combined with the mean values in the atmospheric concentrations of the years 1985-1987 from Alert (Canada, $\left.82.45^{\circ} \mathrm{N}\right)$ and South Pole $\left(89.98^{\circ} \mathrm{S}\right)$ (Dlugokencky et al., 2011), and immediately find $\tau=10.0 \mathrm{yr}$ and $\tau_{\mathrm{ex}}=1.8 \mathrm{yr}$. We keep these values fixed during all model runs. The dependence of $s_{\mathrm{n}}$ and $s_{\mathrm{s}}$ on the parameters $\tau$ and $\tau_{\mathrm{ex}}$ is described in Sect. 4.1. An alternative initialisation with a source strength estimate $\left(548 \mathrm{Tg} \mathrm{yr}^{-1}\right)$ and a source distribution estimate for the year 2004 from a more recent $\mathrm{CH}_{4}$ budget modelling study (Spahni et al., 2011) yields $\tau=9.5 \mathrm{yr}$ and $\tau_{\mathrm{ex}}=1.7 \mathrm{yr}$, which compare well with the above initialisation. Note that other studies using a two-box model (Sowers, 2010) lower the concentration measured in Greenland $c_{\mathrm{n}}$ 
by a fixed portion of the IPD to obtain the mean concentration of the northern box. This takes into account the latitudinally decreasing concentration from north to south within the northern box observed today. Due to the lack of the anthropogenic sources, this latitudinal concentration gradient might have been smaller in the past, however it might still have been present since it is mainly an effect of the sink, which is significantly lower at high latitudes. We did not lower the ice core derived $c_{\mathrm{n}}$ in our model study, but took this effect into account in our model initialisation by allowing for a relatively large $\tau_{\text {ex }}$ of $1.8 \mathrm{yr}$. This essentially implies that this exchange time is representing the time needed for $\mathrm{CH}_{4}$ to sustain the measured interpolar, and not a mean interhemispheric concentration difference. If we had lowered $c_{\mathrm{n}}$ by $26 \%$ of the IPD (Sowers, 2010), the initialisation would yield $\tau_{\mathrm{ex}}=1.3 \mathrm{yr}$, which is well in range with the value from Geller et al. (1997) (1.3 $\pm 0.1 \mathrm{yr})$ derived from sulfur hexafluoride $\left(\mathrm{SF}_{6}\right)$.

The model is run for steady state conditions, which simplifies Eq. (3) and provides the sources:

$s_{\mathrm{n}}\left(c_{\mathrm{n}}, \mathrm{IPD}, \tau, \tau_{\mathrm{ex}}\right)=m^{*} \cdot\left(\frac{1}{\tau} \cdot c_{\mathrm{n}}+\frac{1}{\tau_{\mathrm{ex}}} \cdot \mathrm{IPD}\right)$

and

$s_{\mathrm{S}}\left(c_{\mathrm{s}}, \mathrm{IPD}, \tau, \tau_{\mathrm{ex}}\right)=m^{*} \cdot\left(\frac{1}{\tau} \cdot c_{\mathrm{s}}-\frac{1}{\tau_{\mathrm{ex}}} \cdot \mathrm{IPD}\right)$.

The calculated source strengths corresponding to the mean concentrations of the specified time intervals (Fig. 1) are shown in Fig. 5a and summarised in Table 1. The errors for $s_{\mathrm{n}}$ and $s_{\mathrm{S}}$ in this top-down simulation are calculated from the errors of $c_{\mathrm{n}}$ and $c_{\mathrm{s}}$.

Vice versa in a bottom-up simulation, from a given source distribution the two-box model provides the concentrations $c_{\mathrm{n}}, c_{\mathrm{s}}$ and the IPD and rIPD:

$\operatorname{IPD}\left(s_{\mathrm{n}}, s_{\mathrm{s}}, \tau, \tau_{\mathrm{ex}}\right)=\frac{1}{m^{*}} \cdot\left(s_{\mathrm{n}}-s_{\mathrm{S}}\right) \cdot \frac{\tau}{1+2 \frac{\tau}{\tau_{\mathrm{ex}}}}$

and

$\operatorname{rIPD}\left(s_{\mathrm{n}}, s_{\mathrm{s}}, \tau, \tau_{\mathrm{ex}}\right)=2 \cdot \frac{s_{\mathrm{n}}-s_{\mathrm{s}}}{s_{\mathrm{n}}+s_{\mathrm{s}}} \cdot \frac{1}{1+2 \frac{\tau}{\tau_{\mathrm{ex}}}}$.

Hence, in this two-box model both the IPD and the rIPD are proportional to the difference $s_{\mathrm{n}}-s_{\mathrm{S}}$, but only the rIPD is independent of global source scaling. This means that if $s_{\mathrm{n}}$ and $s_{\mathrm{S}}$ are scaled by the same factor, the rIPD stays constant.

For short exchange times, $\tau_{\mathrm{ex}}$, the IPD is not especially sensitive to the atmospheric lifetime $\tau$. However, for a given value of $\tau_{\mathrm{ex}}$, rIPD decreases with increasing $\tau$ as the extent to which $\mathrm{CH}_{4}$ is mixed between hemispheres increases (and hence its concentration is homogenised globally).

\subsection{Sensitivity of $\mathrm{CH}_{4}$ sources to $\tau$ and $\tau_{\mathrm{ex}}$}

Figure 6 shows the sensitivity of the sources $s_{\mathrm{n}}$ and $s_{\mathrm{s}}$, calculated in Eq. (6) and Eq. (7), to the parameters $\tau$ and $\tau_{\mathrm{ex}}$ for three different time intervals (BA, YD, LGM). Relatively small changes in the two parameters have substantial impact on the estimated sources. For both parameters, the sensitivity is stronger for higher IPD. While changes in the atmospheric lifetime $\tau$ of $\mathrm{CH}_{4}$ primarily affect the total source strength, changes in the interhemispheric mixing time $\tau_{\mathrm{ex}}$ affect the source distribution.

Similar sensitivity experiments by Brook et al. (2000) with the three-box model show that for a fixed rIPD the boreal source increases and the tropical source decreases with decreasing $\tau_{\text {ex }}$ (faster interhemispheric mixing). In the two-box model used in this study, assuming a fixed rIPD, $s_{\mathrm{n}}$ would increase and $s_{\mathrm{S}}$ would decrease with decreasing $\tau_{\text {ex }}$ (faster interhemispheric mixing). Conversely, assuming a fixed source distribution, a decrease in $\tau_{\mathrm{ex}}$ (faster interhemispheric mixing) would result in a decrease in the rIPD. Glacial/interglacial changes in $\tau_{\text {ex }}$ could thus have affected the rIPD. If the interhemispheric mixing was faster in glacial times, this would imply that the northern source was stronger and the southern source weaker than estimated in this study. Further work is required to constrain the changes in $\tau_{\mathrm{ex}}$ on glacial/interglacial time scales.

\subsection{Two-box model versus three-box model}

Previous IPD studies used a three-box model to estimate the $\mathrm{CH}_{4}$ source distribution (Chappellaz et al., 1997; Brook et al., 2000; Dällenbach et al., 2000). The three-box model has the advantage that it accounts for the higher sink strength in the tropics compared to the high latitudes. Further, it provides an estimate for the tropical source strength $\left(30^{\circ} \mathrm{N}-\right.$ $30^{\circ} \mathrm{S}$ ), but it is not able to distinguish between northern and southern tropical sources. Moreover, the source term for the southern box $\left(30^{\circ} \mathrm{S}-90^{\circ} \mathrm{S}\right)$ has to be prescribed, because only two measurements (Greenland and Antarctica) exist to constrain the model.

The two-box model, on the other hand, has the advantage that it is more illustrative and can be easily treated analytically. Further, as already stated by Sowers (2010), there is no need to fix one source term. This is necessary in the three-box model due to the missing information on the tropical concentration. Figure $5 \mathrm{~b}$ shows an alternative run with the three-box model using exactly the model configuration from Chappellaz et al. (1997). The southern source $\left(30^{\circ} \mathrm{S}-90^{\circ} \mathrm{S}\right)$ is fixed at $15 \mathrm{Tg} \mathrm{yr}^{-1}$ for the Holocene intervals including the YD and BA periods. For the glacial intervals it is fixed at $12 \mathrm{Tg} \mathrm{yr}^{-1}$. Overall, there is little difference in the output of the two models. The trend in $s_{\mathrm{n}}$ of the two-box model is closely related to the trend in the boreal box of the three-box model (blue lines), while the trend in $s_{\mathrm{S}}$ follows the trend in the tropical box (red and green line). Adding the tropical source equally 

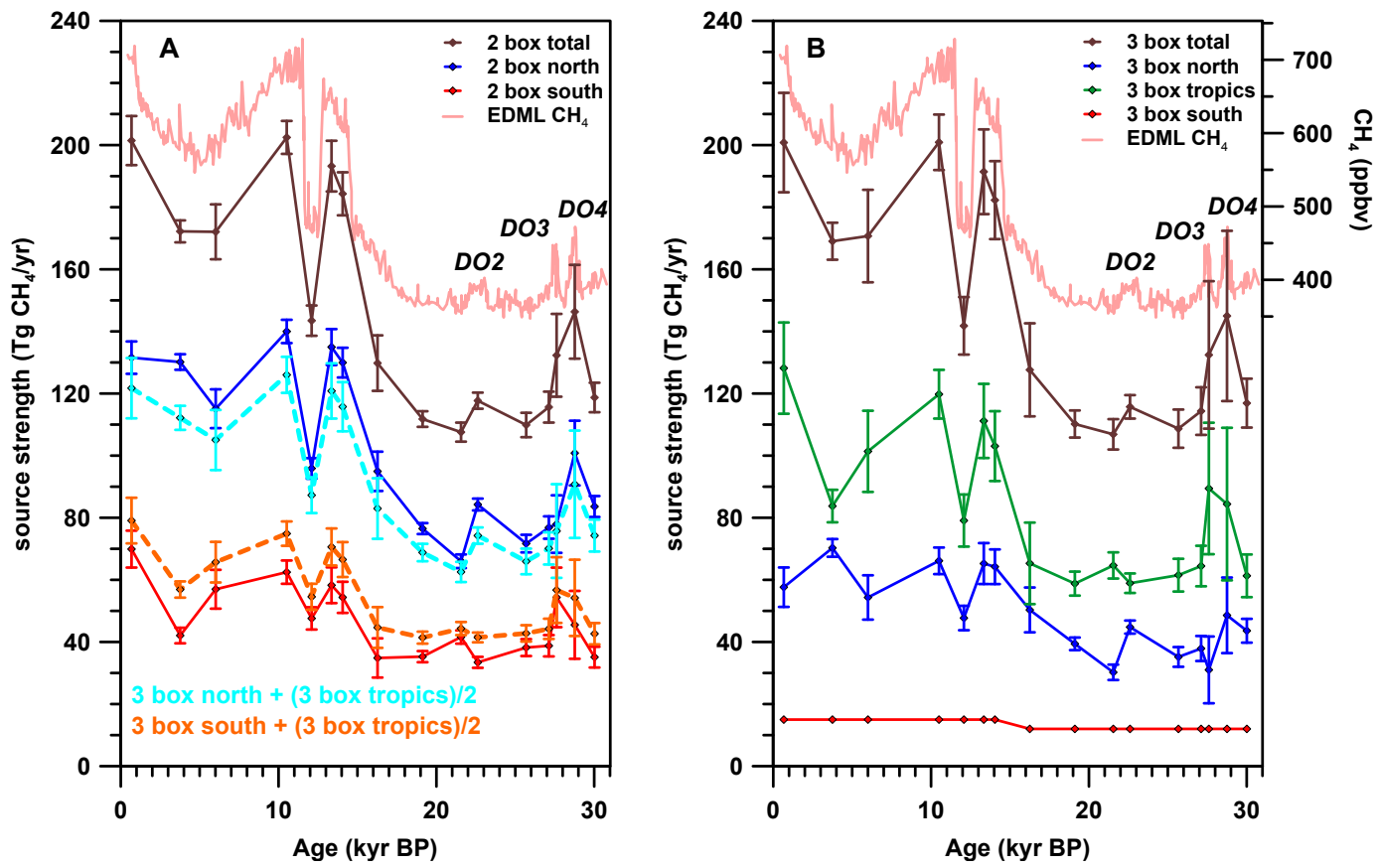

Fig. 5. Comparison of $\mathrm{CH}_{4}$ source strength calculated with the three-box model and the two-box model. On the top of both panels the $\mathrm{CH}_{4}$ concentration from EDML is shown for reference (light red). (A) $\mathrm{CH}_{4}$ source strength calculated with two-box model. Brown: total source, blue: northern source, red: southern source, cyan: boreal source of the three-box model plus half of tropical source of the three-box model, and orange: southern source of the three-box model plus half of the tropical source of the three-box model. $(\mathbf{B}) \mathrm{CH}_{4}$ source strength calculated with three-box model (Chappellaz et al., 1997). Brown: total source, blue: northern source $\left(30^{\circ} \mathrm{N}-90^{\circ} \mathrm{N}\right)$, green: tropical source $\left(30^{\circ} \mathrm{S}-30^{\circ} \mathrm{N}\right)$, and red: southern source $\left(90^{\circ} \mathrm{S}-30^{\circ} \mathrm{S}\right)$.

to the northern and southern sources of the three-box model, the sources $s_{\mathrm{n}}$ and $s_{\mathrm{S}}$ of the two-box model are well reproduced (cyan and orange line in Fig. 5a).

\section{Discussion}

Figure 7 summarises the results of this study. Figure 7a shows the two new NGRIP and EDML $\mathrm{CH}_{4}$ concentration records again for reference, and Fig. 7b displays the resulting source distribution. To put the variations in the concentration, IPD and rIPD on a common scale, we define interval (V) (20.4-17.8 kyrBP) as the reference interval (index ref) and calculate the ratios $c_{\mathrm{s}} / c_{\mathrm{s} \text {,ref }}$, IPD/IPD ${ }_{\text {ref }}$

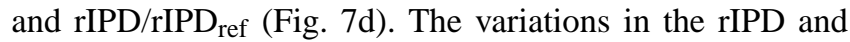
$\mathrm{CH}_{4}$ source strength are compared with the variations in the speleothem monsoon records from Hulu cave (China) at $32^{\circ} \mathrm{N}$ (Wang et al., 2001) and Caverna Botuverá (Brazil) at $27^{\circ} \mathrm{S}$ (Wang et al., 2007) and the isotopic composition $\left(\delta^{13} \mathrm{CH}_{4}\right)$ of $\mathrm{CH}_{4}$ (Fischer et al., 2008), which are shown in Fig. 7c. The monsoon records provide important information on the availability of water in the major tropical $\mathrm{CH}_{4}$ source regions. The isotopic composition of $\mathrm{CH}_{4}$ is influenced by the relative strengths of the different $\mathrm{CH}_{4}$ sources with different isotopic signatures. However, also changes in the isotopic signature of individual methane sources over time (Schaefer and Whiticar, 2008) or changes in the relative strengths of different methane sinks (e.g. oxidation by atomic chlorine or the hydroxyl radical) showing greater/lesser preference for removing ${ }^{12} \mathrm{CH}_{4}$ over ${ }^{13} \mathrm{CH}_{4}$ can influence $\delta^{13} \mathrm{CH}_{4}$ (e.g. Allan et al., 2001; Levine et al., 2011).

\subsection{Variations in the rIPD and $\mathrm{CH}_{4}$ source strength}

To first order, we observe a relatively stable rIPD value throughout the record (Fig. 3). In particular, there is less variability in the rIPD than in earlier studies, since we showed that the previously measured rIPD value during the LGM (Dällenbach et al., 2000) was too low (Sect. 3.3). The stability of the rIPD is also expressed in Fig. 7d, which shows that the ratio rIPD/rIPD ref (pink curve) is not statistically significantly different from 1 for the majority of the time intervals. The ratio IPD/IPD ${ }_{\text {ref }}$ (green curve), on the other hand, shows a relatively large correlation $\left(R^{2}=0.8\right)$ with the normalised EDML $\mathrm{CH}_{4}$ concentration $c_{\mathrm{S}} / c_{\mathrm{s}, \text { ref }}$ (light red curve in the background). This points to a relatively stable source distribution despite changing total emission strengths, i.e. if the concentration changes, the sources $s_{\mathrm{n}}$ and $s_{\mathrm{S}}$ change by a similar factor.

To second order, we identify notable exceptions in the overall stability of the rIPD. The most outstanding feature is the low rIPD in the interval $21.9-21.2 \mathrm{kyrBP}$ after DO 

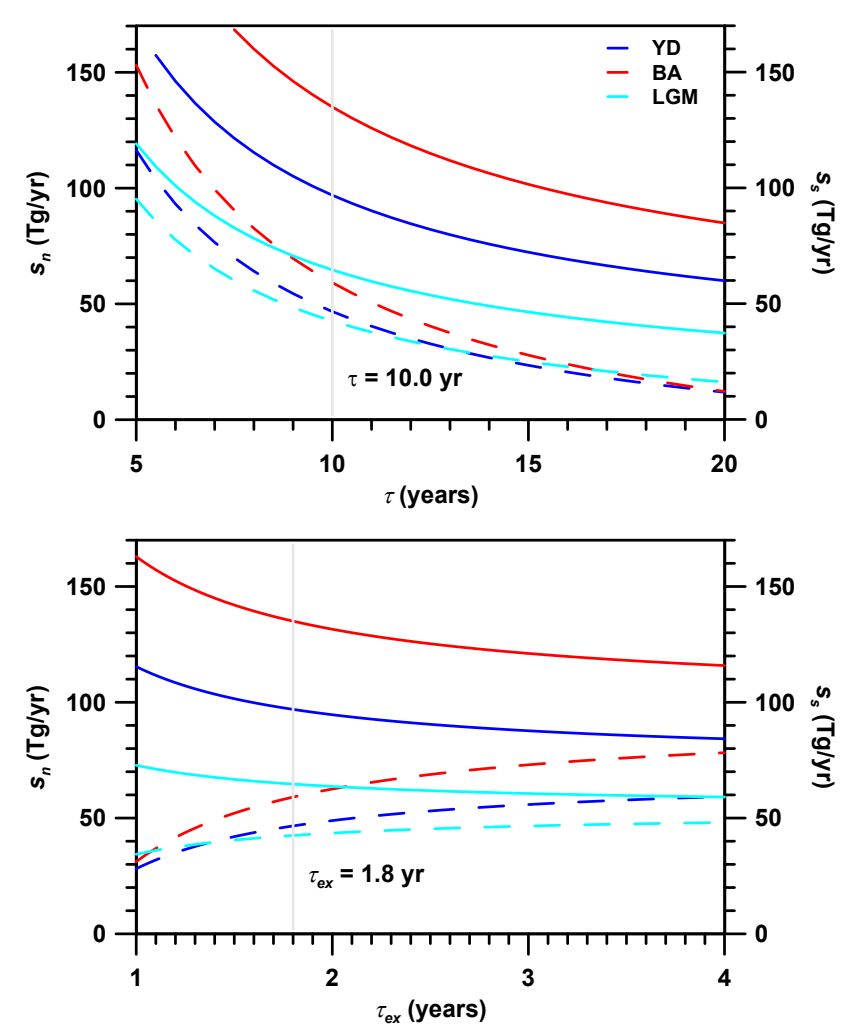

Fig. 6. Sensitivity of $\mathrm{CH}_{4}$ sources to $\tau$ and $\tau_{\mathrm{ex}}$. Source distribution (solid lines: $s_{\mathrm{n}}$, dashed lines: $s_{\mathrm{S}}$ ) calculated for three different climate states (blue: YD, red: BA, light blue: LGM; concentrations from Table 1) depending on $\tau$ (upper panel) and $\tau_{\mathrm{ex}}$ (lower panel). While one parameter is varied, the other is set to $\tau=10.0 \mathrm{yr}$ or $\tau_{\mathrm{ex}}=1.8 \mathrm{yr}$ (grey lines), accordingly. The model is run at these values, which have their origin in the initialisation with a present-day source distribution from Fung et al. (1991).

event 2. Both the decrease in the rIPD from DO event 2 to this interval and the subsequent increase in the rIPD from this interval to the glacial reference interval 20.4-17.8 kyr BP are statistically significant. The same is true for the increase in the rIPD from the interval 27.0-24.4 kyrBP to the DO event 2 .

In the following we discuss in detail the time span around the LGM, the Termination 1 (T1), and the DO events.

\subsection{1 rIPD around the LGM}

In the interval 21.9-21.2 kyr BP, we observe a pronounced minimum in the rIPD. Together with this pronounced minimum, but not significantly different from the reference interval, the interval 27.0-24.4 kyr BP shows one of the lowest rIPD values observed in the record. Especially in North America, the boreal source is likely to be suppressed by the wide extent of the ice sheets and permafrost regions and hence is likely to contribute to the reduction of the rIPD (Dällenbach et al., 2000; Fischer et al., 2008). Further, a bottom-up modelling study supports a southward shift of the boreal and tropical sources in the LGM, which was caused by a southward shift of the westerlies because of the large ice sheet extent and by a southward displacement of the ITCZ, respectively (Weber et al., 2010).

A southward displacement of the ITCZ could influence the rIPD in two ways. First, it would shift the optimal conditions for $\mathrm{CH}_{4}$ emissions to more southerly latitudes. The effect on the rIPD might be amplified by the coincident latitudinal dislocation of the monsoon systems. Second, a southward shift in the ITCZ would increase the volume of the northern box at the expense of the southern box. A $1^{\circ}$ southward shift would change the volumes in the northern and southern box by about $2 \%$ in opposite directions. For $5^{\circ}$ the volume change of a box is $9 \%$ and for $10^{\circ}$ it is $17 \%$. If we assume that the mixing time of a box is proportional to its volume, the two-box model simulates the volume changes caused by the ITCZ shifts by using different mixing times $\tau_{\text {ex,n }}$ and $\tau_{\mathrm{ex}, \mathrm{s}}$ for the northern and southern box. Assume now that the ITCZ was exactly at the equator during the glacial reference interval (20.4-17.8 kyrBP). If we take the northern and southern emission strengths of the glacial reference interval from Table $1\left(s_{\mathrm{n}}=76.5 \mathrm{Tg} \mathrm{yr}^{-1}, s_{\mathrm{s}}=35.3 \mathrm{Tg} \mathrm{yr}^{-1}\right)$ and vary the volumes of the northern and southern box, respectively, we find an alternative way to explain the rIPD variations of the glacial neighbour intervals. We need a $8.5^{\circ}$ southward shift of the ITCZ to explain the rIPD in the interval 21.9$21.2 \mathrm{kyrBP}$. Analogous, a southward shift of $4^{\circ}$ is needed for the interval 27.0-24.4 kyrBP and a northward shift of $3.5^{\circ}$ for DO event 2.

During the Holocene, speleothem records from the Northern Hemisphere (Southern Hemisphere) show a long-term decrease (increase) in precipitation in line with Northern Hemisphere (Southern Hemisphere) summer insolation (Burns, 2011). This points to a long-term southward shift of the mean position of the ITCZ during the Holocene. Along the same line, Singarayer et al. (2011) explain the increase in the $\mathrm{CH}_{4}$ concentration during the Holocene, which started at $5 \mathrm{kyr} \mathrm{BP}$, with increased emissions from the southern low latitudes due to precession-induced modification of seasonal precipitation. While the northern source strength remains at a constant level, they state that the additional emissions stem from the Southern Hemisphere due to wetter conditions. Burns (2011) remarks that the scenario of southward migration of $\mathrm{CH}_{4}$ sources could explain the reduction of the rIPD from the interval 5-2.5 kyrBP to the interval 1-0.25 kyr BP (Chappellaz et al., 1997). Chappellaz et al. (1997) attribute the temporarily higher rIPD during the interval 5-2.5 kyrBP to boreal wetland expansion. Similarly as during the Late Holocene, the Southern Hemisphere summer insolation reaches a maximum at approximately $20 \mathrm{kyr} B P$. As in the Holocene, the enhanced precipitation connected to this maximum in the southern low latitudes could boost the emissions from the Southern Hemisphere. Indeed the summer monsoon strength at Caverna Botuverá (South America) is relatively high between $27-14 \mathrm{kyrBP}$ (compared to the full 


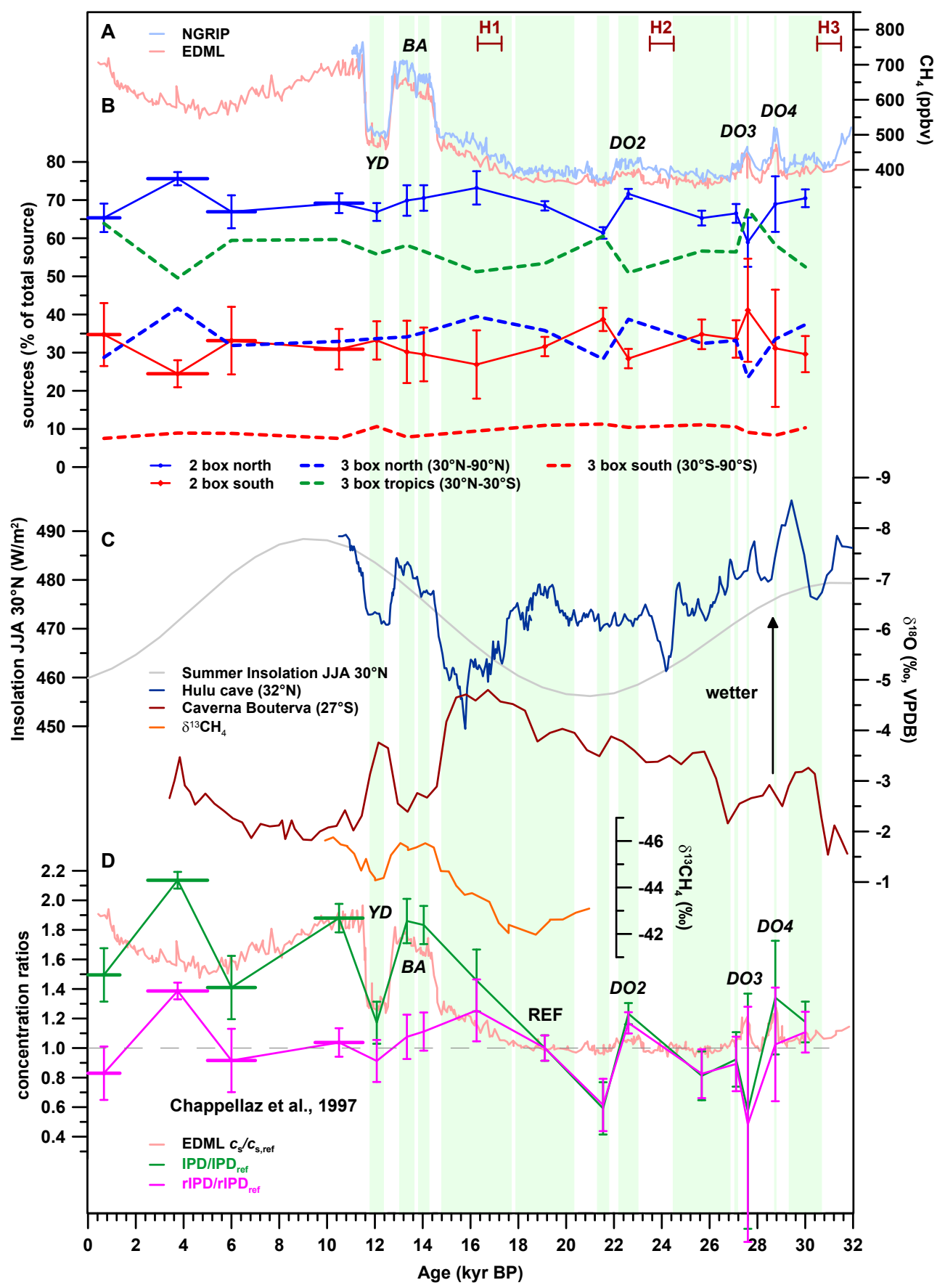

Fig. 7. Variations in the $\mathrm{CH}_{4}$ source strength. Green shaded areas are the same as in Fig. 1 and indicate the time interval, wherein each point is the mean value of its time interval (Table 1). On the left side, the four Holocene values from Chappellaz et al. (1997) are also included, where the horizontal bars indicate the time interval. (A) $\mathrm{CH}_{4}$ concentrations from EDML (red, EPICA Community Members, 2006, and new data) and NGRIP (blue, Schilt et al., 2010b, and new data). (B) Source strengths calculated by the two-box and the three-box model as fractions of the total source strength. Solid blue: northern source of two-box model, solid red: southern source of two-box model, dashed blue: northern source $\left(30^{\circ} \mathrm{N}-90^{\circ} \mathrm{N}\right)$ of three-box model, dashed green: tropical source $\left(30^{\circ} \mathrm{S}-30^{\circ} \mathrm{N}\right)$ of three-box model, and dashed red: southern source $\left(90^{\circ} \mathrm{S}-30^{\circ} \mathrm{S}\right)$ of three-box model. (C) Grey: northern summer insolation $\left(30^{\circ} \mathrm{N}\right)$ (Quinn et al., 1991), dark blue: monsoon record from Hulu Cave (Wang et al., 2001), dark red: monsoon record from Caverna Boutervá (Wang et al., 2007), and orange: $\delta^{13} \mathrm{CH}_{4}$

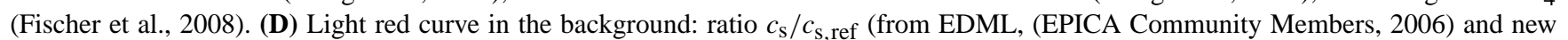

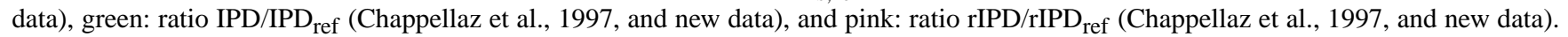
Interval (V) from Table 1 is used as the reference interval, to put all the ratios on the same scale. With the exception of the monsoon records, which are shown on their original time scales, all data are synchronised to the unified EDML gas age scale derived by Lemieux-Dudon et al. (2010). 
glacial record), while the summer monsoon strength at Hulu cave (China) is very weak during this period (Fig. 7c).

The increase in the rIPD from the time interval 21.9$21.2 \mathrm{kyrBP}$ to the time interval $20.4-17.8 \mathrm{kyrBP}$ is statistically significant and happens several thousand years before the transition into the Holocene and in the absence of rapid climatic changes like a DO event, although we recognise a small peak in the $\mathrm{CH}_{4}$ concentration at $21 \mathrm{kyrBP}$ (Fig. 1). The increase in the mean $\mathrm{CH}_{4}$ concentration from the time interval 21.9-21.2 kyr BP to the time interval 20.4$17.8 \mathrm{kyrBP}$ is only $15 \mathrm{ppbv}$. The consequent increase in $s_{\text {tot }}$ of $4 \mathrm{Tg} \mathrm{yr}^{-1}$ arises from an increase in $s_{\mathrm{n}}$ of $11 \mathrm{Tg} \mathrm{yr}^{-1}$ and a simultaneous decrease in $s_{\mathrm{S}}$ of $7 \mathrm{Tg} \mathrm{yr}^{-1}$ in our two-box model. The three-box model suggests that this increase stems from the boreal region. However, changes in low latitudes could also have contributed to changes in the rIPD, connected to shifts in the ITCZ as explained above. Due to synchronisation uncertainties between ice core and speleothem records and the only weakly expressed variations in the speleothem signals during this time period as well as uncertainties in the interpretation of speleothem records (Clemens et al., 2010), we do not attempt to interpret any trends in view of changes in monsoon strength.

\subsection{2 rIPD during Termination 1}

The new data suggest a fairly stable mean rIPD level of $6.5 \pm 0.8 \%$ (20.4-11.7 kyrBP, intervals (I)-(V)) during T1, which is well expressed in the ratio rIPD/rIPD ref $_{\text {close to one }}$ (Fig. 7d). With the exception of the higher value during the late Holocene (5-2.5 kyr BP), previous Holocene reconstructions show a similar rIPD as well (Chappellaz et al., 1997). It is also close to the present day anthropogenically modified rIPD $(7.6 \pm 0.5 \%)$ with global emissions 2.5 times as large. Taken at face value and assuming a constant atmospheric lifetime (Levine et al., 2011) and interhemispheric mixing time, this could imply that the source distributions of the Holocene, BA and YD period were not so different from the source distribution at the end of the last glacial (20.4$17.8 \mathrm{kyr} B P)$. Note that the YD period still shows the lowest rIPD during T1 in line with Northern Hemisphere cold conditions. On the other hand, the BA shows a relatively high rIPD despite a still more extended northern continental ice coverage in the BA compared to the Holocene. It is also notable that the monsoon records from the Northern and Southern Hemispheres show a pronounced anti-correlation during the BA-YD-Holocene transition. The southward displacement of wet conditions might contribute to the slightly lower rIPD during the YD.

The interval 17.8-14.7 kyrBP(IV), which contains Heinrich event $1(\mathrm{H} 1)$ and shows a slow $100 \mathrm{ppbv}$ increase in the $\mathrm{CH}_{4}$ concentration, has also a relatively high rIPD value, although with a large uncertainty due to the synchronisation uncertainty (Sects. 2.1 and 3.1). To agree with both the higher concentration and the higher rIPD value compared to the glacial reference interval (20.4-17.8 kyrBP), an increase in $s_{\mathrm{n}}$ is needed. The catastrophic drought in Afro-Asian monsoon regions (Stager et al., 2011; Wang et al., 2001) related to $\mathrm{H} 1$ tends to weaken the low-latitude northern source. This points to an increase in the boreal source to establish the increase in $s_{\mathrm{n}}$.

The isotopic $\delta{ }^{13} \mathrm{CH}_{4}$ data from Fischer et al. (2008) show a substantial decrease from the LGM to the Holocene (Fig. 7c). Largely based on the zero rIPD during the LGM and the strong increases in the rIPD and in the $\mathrm{CH}_{4}$ concentration during T1 (Dällenbach et al., 2000), Fischer et al. (2008) suggested that the decrease in the isotopic composition $\delta^{13} \mathrm{CH}_{4}$ is most likely due to a relatively strong increase in the light boreal wetland $\mathrm{CH}_{4}$ source (compared to a relatively moderate increase in the tropical wetland source). Our new rIPD data would still support a relatively strong increase in the boreal source strength during the interval 17.8-14.7 kyr BP in line with the relatively large portion of the LGM to Holocene decrease in the isotopic signature completed during this interval. However, due to the almost identical rIPD during the BA and the Holocene compared to the glacial interval 20.4$17.8 \mathrm{kyr} B P$, it is highly unlikely that the changes in the isotopic signature can be fully attributed to an increase in the boreal wetland source. A similar increase in the boreal and tropical source strength is visible in the three-box model run. While the boreal and tropical sources account for $35.8 \%$ and $53.4 \%$ of the total source during the glacial reference interval 20.4-17.8 kyr BP, respectively, they reach almost unchanged values of $35.2 \%$ and $56.5 \%$ during the BA period (Fig. $7 \mathrm{~b}$ ).

Note that a substantial decrease in interhemispheric exchange time $\tau_{\mathrm{ex}}$ from the LGM to the Holocene could still pretend a constant rIPD during T1, although the boreal source would have increased by a higher factor compared to the tropical source strength. Furthermore, the interpretation of $\delta^{13} \mathrm{CH}_{4}$ is not yet unambiguous and, for instance, a large shift in the ratio of $\mathrm{C} 3$ to $\mathrm{C} 4$ plants could also explain part of the isotopic changes over T1 (Sowers, 2010; Schaefer and Whiticar, 2008), as could a decrease in biomass burning - a particularly rich source of ${ }^{13} \mathrm{CH}_{4}$ - or an increase in the fraction of methane oxidised by atomic chlorine, which shows a particularly strong preference for removing ${ }^{12} \mathrm{CH}_{4}$ over ${ }^{13} \mathrm{CH}_{4}$ (e.g. Levine et al., 2011).

\subsection{3 rIPD variations during DO events}

The increase in the rIPD from the interval 27.0-24.4 kyrBP $(5.0 \pm 0.8 \%)$ to the DO event $2(7.1 \pm 0.5 \%)$ is relatively weak but statistically significant. The coincident increase in the concentration is caused by an increase in $s_{\mathrm{n}}$ of $12 \mathrm{Tg} \mathrm{yr}^{-1}$ and a slight decrease in $s_{\mathrm{s}}$ by $5 \mathrm{Tg} \mathrm{yr}^{-1}$ in our two-box model.

During DO events, the active Atlantic meridional overturning circulation (AMOC) transports heat into the Northern Hemisphere (Stocker and Johnsen, 2003), which should enhance the northern $\mathrm{CH}_{4}$ emissions. In the three-box model run by Dällenbach et al. (2000), the higher rIPD values 
during DO events are caused by a stronger increase in the boreal source strength compared to the increase in the tropical source strength. Similarly, using the rIPD and isotopic $\delta \mathrm{D}\left(\mathrm{CH}_{4}\right)$ data as constraints, Bock et al. (2010) find an increase of boreal wetland emissions by a factor of 6 (from $5 \mathrm{Tg} \mathrm{yr}^{-1}$ to $32 \mathrm{Tg} \mathrm{yr}^{-1}$ ) combined with a moderate increase of tropical wetland emissions by a factor of 1.4 (from $84 \mathrm{Tg} \mathrm{yr}^{-1}$ to $118 \mathrm{Tg} \mathrm{yr}^{-1}$ ) for DO event 8 . In view of the too low northern stadial $\mathrm{CH}_{4}$ concentrations in the Dällenbach et al. (2000) record, which were also used by Bock et al. (2010), this strong increase in boreal $\mathrm{CH}_{4}$ emissions has to be questioned. In our measurements for DO event 2 , we find a $30 \%$ increase in the boreal source strength (Fig. 5b). The three-box model shows an increase in the relative contribution of boreal emissions from $32.4 \%$ to $38.7 \%$ and a decrease in the relative contribution of tropical emissions from $56.6 \%$ to $50.9 \%$ from the interval $27.0-24.4 \mathrm{kyr} B \mathrm{P}$ to the DO event 2.

However, the equally high rIPD value for DO event 2 compared to other DO events (Sect. 3.3) is surprising, since DO event 2 occurs in a time of very large ice sheet extent, and thus, an equally strong impact of boreal wetland sources for DO event 2 compared to other DO events appears not to be straightforward. Thus, the question arises if the threebox model overestimates the increase in the boreal emissions during DO events. Several studies (Otto-Bliesner and Brady, 2010; Broccoli et al., 2006; Schmidt and Spero, 2011) suggest also latitudinal swings in the ITCZ and the monsoon systems on millennial time scales. During DO events, the ITCZ is located in a more northward position coincident with increased northern summer monsoon strength compared to the cold stadial intervals. As described in Sect. 5.1.1, we hypothesise that the source redistribution within lower latitudes and the changes in the size of the northern and southern hemispheric box connected to shifts in the ITCZ also contribute to the subtle variations in the rIPD during DO events.

\subsubsection{Long-term rIPD trend}

In this section we discuss a potential long-term influence of northern summer insolation on the latitudinal distribution of the $\mathrm{CH}_{4}$ sources. If such an influence exists, it should be mirrored in the rIPD. In periods of low northern summer insolation, we would expect lower emissions from the Northern Hemisphere due to shorter emission seasons.

The comparison of the rIPD to northern summer insolation is motivated by a bottom-up modelling study (Singarayer et al., 2011), which estimates the $\mathrm{CH}_{4}$ emissions over the last $120 \mathrm{kyr}$ BP for different source regions. Their model accounts for orbital forcing, greenhouse gas concentrations, ice sheet extent and sea level, but it neglects millennial scale variability. To asses a long-term trend in the rIPD from their results, we use the sum of all northern and southern hemispheric emissions in the Singarayer et al. (2011) study as an input for our two-box model for the northern and the southern box,

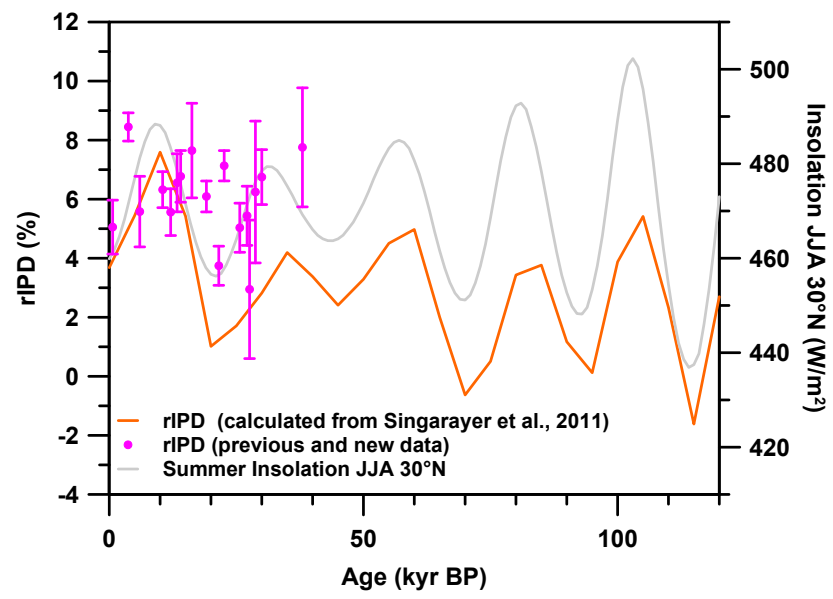

Fig. 8. rIPD long-term trend estimated from the $\mathrm{CH}_{4}$ source distribution by Singarayer et al. (2011). The rIPD (orange) was calculated according to Eqs. (8) and (9). Measured rIPD data (Brook et al., 2000; Chappellaz et al., 1997, and new data) are shown in pink. Northern summer insolation (JJA) $\left(30^{\circ} \mathrm{N}\right)$ is plotted in grey (Quinn et al., 1991).

respectively. Figure 8 shows the clear variation along with the precessional cycle in the calculated rIPD (orange line) together with the northern summer insolation curve (grey) (Quinn et al., 1991).

In contrast, the ice core derived rIPD, covering only the last $30 \mathrm{kyrBP}$, shows less variation. However, there are a few patterns which show a relation to the insolation curve. As already discussed in Sect. 5.1.1, the pronounced minimum in the rIPD between $21.9-21.2 \mathrm{kyrBP}$ is approximately at the time of a minimum in northern summer insolation. Further, with the exception of DO event 2 , there is a decreasing trend in the rIPD between roughly $30-20 \mathrm{kyrBP}$ in line with northern summer insolation. Less clear and again with an exception (5-2.5 kyr BP), the same could be true during the Holocene between roughly $10-0 \mathrm{kyrBP}$. The increasing northern summer insolation between roughly $20-10 \mathrm{kyrBP}$, however, has no clear counterpart in the rIPD due to the stability of the rIPD during T1.

In summary, our data neither support nor fully rule out a possible long-term influence of northern summer insolation on the rIPD. The limited temporal coverage of our data set combined with the weak variation and the superimposed processes on millennial time scales do not allow for any conclusive remarks on this topic. High-resolution records produced in the way presented here from both poles, and over the whole last glacial cycle, are needed to address this question. The importance of the rIPD as a constraint for models is a strong motivation for future high-resolution measurements. 


\section{Conclusions}

The sampling and measurement strategy carried out for this study was designed for an optimum determination of the interpolar difference in $\mathrm{CH}_{4}$. The quasi-simultaneously analysed samples from Greenland and Antarctica increase the confidence in the accuracy of our values. We suggest that this procedure is essential for future rIPD studies. Further, the high resolution of our records improves the synchronisation of the gas ages between the NGRIP and EDML ice cores and determines the IPD with unprecedented precision and temporal resolution.

We show that the previous rIPD estimate $(-0.8 \pm 1.0 \%)$ during the LGM (21.9-17.8 kyrBP) from Dällenbach et al. (2000) was significantly too low. The revised estimate is between $3.7 \pm 0.7 \%$ and $6.1 \pm 0.5 \%$. Consequently, there is less variability in the rIPD and $\mathrm{CH}_{4}$ source distribution than previously reported, and boreal wetland sources in the Northern Hemisphere were never completely shut off during the glacial. The strongest variations in the rIPD (28$18 \mathrm{kyrBP}$ ) are observed during a time interval where only smaller changes in the $\mathrm{CH}_{4}$ concentration occurred. The lowest rIPD $(3.7 \pm 0.7 \%)$ is observed between 21.9-21.2 kyr BP, just after DO event 2. This is during a time when the ice sheet extent was at its maximum and the northern summer insolation at its minimum. A shift back to northern sources happens around $21 \mathrm{kyrBP}$, several millennia prior to the transition into the Holocene.

The rIPD during Termination 1 is fairly stable $(6.5 \pm$ $0.8 \%$ ), although somewhat lower during the YD. It is also close to the present-day anthropogenically modified rIPD $(7.6 \pm 0.5 \%)$ with global emissions 2.5 times as large. Assuming a constant atmospheric lifetime of $\mathrm{CH}_{4}$ (Levine et al., 2011), the stability of the rIPD could imply that the interhemispheric source distribution of the Holocene was not so different from the source distribution of the last glacial, although with increasing source strengths both south and north of the equator. In agreement with Brook et al. (2000), we conclude that the increase in the $\mathrm{CH}_{4}$ concentrations over Termination 1 is established by increases in the boreal and the tropical sources by approximately the same factor.

The rIPD values for DO event $2(7.1 \pm 0.5 \%)$ and 4 $(6.2 \pm 2.4 \%)$ are well in the range of previous results for DO event $8(7.8 \pm 2.0 \%)$ (Brook et al., 2000) and with the mean value over several DO events $(7.5 \pm 2.1 \%)$ (Dällenbach et al., 2000). The rIPD value for DO event $3(2.9 \pm 2.3 \%)$ is lower but has a large uncertainty connected to the short duration of this event.

We hypothesise that latitudinal shifts in the ITCZ and the monsoon system contribute, either by dislocation of the $\mathrm{CH}_{4}$ source regions or, in case of the ITCZ, also by changing the relative atmospheric volumes of the Northern and Southern Hemispheres, to the subtle variations in the rIPD on glacial/interglacial as well as on millennial time scales.
Table A1. List of tie points for $\mathrm{CH}_{4}$ synchronisation of NGRIP to unified EDML gas age scale (Lemieux-Dudon et al., 2010).

\begin{tabular}{|c|c|c|c|}
\hline $\begin{array}{l}\text { NGRIP depth } \\
\text { (m) }\end{array}$ & $\begin{array}{c}\text { EDML depth } \\
\text { (m) }\end{array}$ & $\begin{array}{l}\text { Gas age } \\
\text { (yr BP) }\end{array}$ & $\begin{array}{c}\text { Uncertainty } \\
\text { (yr) }\end{array}$ \\
\hline 1481.2 & 692.2 & 11067 & 50 \\
\hline 1502.6 & 703.6 & 11334 & 50 \\
\hline 1514.7 & 711.2 & 11490 & 50 \\
\hline 1518.0 & 716.6 & 11592 & 50 \\
\hline 1519.7 & 724.0 & 11707 & 50 \\
\hline 1540.1 & 759.2 & 12449 & 50 \\
\hline 1553.2 & 772.0 & 12835 & 50 \\
\hline 1560.4 & 775.6 & 12943 & 50 \\
\hline 1580.2 & 791.5 & 13397 & 50 \\
\hline 1597.8 & 803.2 & 13735 & 50 \\
\hline 1627.5 & 823.7 & 14367 & 50 \\
\hline 1630.2 & 827.3 & 14472 & 50 \\
\hline 1641.2 & 835.7 & 14705 & 50 \\
\hline 1693.5 & 938.7 & 17804 & 500 \\
\hline 1762.8 & 995.2 & 20414 & 200 \\
\hline 1770.5 & 1005.9 & 20889 & 50 \\
\hline 1780.4 & 1014.0 & 21218 & 50 \\
\hline 1792.5 & 1031.2 & 21872 & 50 \\
\hline 1796.9 & 1037.1 & 22112 & 50 \\
\hline 1826.6 & 1067.0 & 23097 & 50 \\
\hline 1828.8 & 1071.0 & 23237 & 50 \\
\hline 1868.4 & 1139.2 & 26956 & 50 \\
\hline 1882.7 & 1146.7 & 27261 & 200 \\
\hline 1890.4 & 1151.9 & 27579 & 50 \\
\hline 1893.7 & 1159.7 & 28091 & 50 \\
\hline 1900.3 & 1169.0 & 28561 & 50 \\
\hline 1906.9 & 1171.7 & 28699 & 50 \\
\hline 1911.3 & 1174.0 & 28833 & 50 \\
\hline 1919.0 & 1181.9 & 29240 & 50 \\
\hline 1937.7 & 1195.6 & 30031 & 50 \\
\hline 1944.9 & 1207.6 & 30771 & 200 \\
\hline
\end{tabular}

\section{Appendix A}

\section{Supplementary data}

NGRIP and EDML $\mathrm{CH}_{4}$ records can be downloaded from the website of the World Data Center for Paleoclimatology at www.ncdc.noaa.gov/paleo.

\section{Supplementary material related to this article is available online at: http://www.biogeosciences.net/9/ 3961/2012/bg-9-3961-2012-supplement.zip.}


Acknowledgements. We thank Jérôme Chappellaz for helpful comments. The very detailed and constructive review comments by J. G. Levine and L. Mitchell have improved the presentation of the material. This work, which is a contribution to the North Greenland Ice Core Project (NGRIP) and the European Project for Ice Coring in Antarctica (EPICA), was supported by the University of Bern, the Swiss National Science Foundation, and the Prince Albert II of Monaco Foundation.

NGRIP is coordinated by the Department of Geophysics at the Niels Bohr Institute for Astronomy, Physics and Geophysics, University of Copenhagen. It is supported by Funding Agencies in Denmark (SHF), Belgium (FNRS-CFB), France (IPEV and INSU/CNRS), Germany (AWI), Iceland (RannIs), Japan (MEXT), Sweden (SPRS), Switzerland (SNF) and the United States of America (NSF, Office of Polar Programs). EPICA is a joint European Science Foundation/European Commission scientific program, funded by the EU and by national contributions from Belgium, Denmark, France, Germany, Italy, the Netherlands, Norway, Sweden, Switzerland and the UK. The main logistic support was provided by IPEV and PNRA (at Dome C) and AWI (at Dronning Maud Land). This is EPICA publication no. 290.

Edited by: X. Wang

\section{References}

Allan, W., Lowe, D. C., and Cainey, J. M.: Active chlorine in the remote marine boundary layer: Modeling anomalous measurements of $\delta^{13} \mathrm{C}$ in methane, Geophys. Res. Lett., 28, 3239-3242, 2001.

Bereiter, B., Schwander, J., Lüthi, D., and Stocker, T. F.: Change in $\mathrm{CO}_{2}$ concentration and $\mathrm{O}_{2} / \mathrm{N}_{2}$ ratio in ice cores due to molecular diffusion, Geophys. Res. Lett., 36, L05703. doi:10.1029/2008GL036737, 2009.

Bloom, A. A., Palmer, P. I., Fraser, A., Reay, D. S., and Frankenberg, C.: Large-scale controls of methanogenesis inferred from methane and gravity spaceborne data, Science, 327, 322-325, 2010.

Blunier, T., Chappellaz, J., Schwander, J., Dällenbach, A., Stauffer, B., Stocker, T. F., Raynaud, D., Jouzel, J., Clausen, H. B., Hammer, C. U., and Johnsen, S. J.: Asynchrony of Antarctic and Greenland climate change during the last glacial period, Nature, 394, 739-743, 1998.

Blunier, T., Spahni, R., Barnola, J.-M., Chappellaz, J., Loulergue, L., and Schwander, J.: Synchronization of ice core records via atmospheric gases, Clim. Past, 3, 325-330, doi:10.5194/cp-3-3252007, 2007.

Bock, M., Schmitt, J., Möller, L., Spahni, R., Blunier, T., and Fischer, H.: Hydrogen Isotopes Preclude Marine Hydrate $\mathrm{CH}_{4}$ Emissions at the Onset of Dansgaard-Oeschger Events, Science, 328, 1686-1689, 2010.

Broccoli, A. J., Dahl, K. A., and Stouffer, R. J.: Response of the ITCZ to Northern Hemisphere cooling, Geophys. Res. Lett., 33, L01702, doi:10.1029/2005GL024546, 2006.

Brook, E. J., Harder, S., Severinghaus, J., Steig, E. J., and Sucher, C. M.: On the origin and timing of rapid changes in atmospheric methane during the last glacial period, Global Biogeochem. Cy., 14, 559-572, 2000.
Buiron, D., Chappellaz, J., Stenni, B., Frezzotti, M., Baumgartner, M., Capron, E., Landais, A., Lemieux-Dudon, B., MassonDelmotte, V., Montagnat, M., Parrenin, F., and Schilt, A.: TALDICE-1 age scale of the Talos Dome deep ice core, East Antarctica, Clim. Past, 7, 1-16, doi:10.5194/cp-7-1-2011, 2011.

Burns, S. J.: Speleothem records of changes in tropical hydrology over the Holocene and possible implications for atmospheric methane, Holocene, 21, 735-741, 2011.

Chappellaz, J., Blunier, T., Kints, S., Dällenbach, A., Barnola, J. M., Schwander, J., Raynaud, D., and Stauffer, B.: Changes in the atmospheric $\mathrm{CH}_{4}$ gradient between Greenland and Antarctica during the Holocene, J. Geophys. Res.-Atmos., 102, 15987-15997, 1997.

Clark, P. U., Dyke, A. S., Shakun, J. D., Carlson, A. E., Clark, J., Wohlfarth, B., Mitrovica, J. X., Hostetler, S. W., and McCabe, A. M.: The Last Glacial Maximum, Science, 325, 710 714, 2009

Clemens, S. C., Prell, W. L., and Sun, Y.: Orbital-scale timing and mechanisms driving Late Pleistocene Indo-Asian summer monsoons: Reinterpreting cave speleothem $\delta^{18} \mathrm{O}$, Paleoceanography, 25, PA4207, doi:10.1029/2010PA001926, 2010.

Dällenbach, A., Blunier, T., Flückiger, J., Stauffer, B., Chappellaz, J., and Raynaud, D.: Changes in the atmospheric $\mathrm{CH}_{4}$ gradient between Greenland and Antarctica during the Last Glacial and the transition to the Holocene, Geophys. Res. Lett., 27, 1005-1008, 2000.

Denman, K., Brasseur, G., Chidthaisong, A., Ciais, P., Cox, P., Dickinson, R., Hauglustaine, D., Heinze, C., Holland, E., Jacob, D., Lohmann, U., Ramachandran, D., da Silva Dias, P., Wofsy, S., and Zhang, X.: Couplings between changes in the climate system and biogeochemistry, in: Climate Change 2007: The Physical Science Basis, Contribution of Working Group I to the Fourth Assessment Report of the Intergovernmental Panel on Climate Change, 2007.

Dlugokencky, E. J., Lang, P. M., and Masarie, K. A.: Atmospheric Methane Dry Air Mole Fractions from the NOAA ESRL Carbon Cycle Cooperative Global Air Sampling Network, 19832010, Version: 2011-10-14, Path: ftp://ftp.cmdl.noaa.gov/ccg/ ch4/flask/event/2010), Version: 2011-08-11, 2011.

Enting, I.: On the use of smoothing splines to filter $\mathrm{CO}_{2}$ data, J. Geophys. Res.-Atmos., 92, 10977-10984, 1987.

Barbante, C., Barnola, J.-M., Becagli, S., Beer, J., Bigler, M., Boutron, C., Blunier, T., Castellano, E., Cattani, O., Chappellaz, J., and Dahl-Jensen, D., Debret, M., Delmonte, B., Dick, D., Falourd, S., Faria, S., Federer, U., Fischer, H., Freitag, J., Frenzel, A., Fritzsche, D., and Fundel, F., Gabrielli, P., Gaspari, V., Gersonde, R., Graf, W., Grigoriev, D., Hamann, I., Hansson, M., Hoffmann, G., Hutterli, M. A., Huybrechts, P., Isaksson, E., Johnsen, S., Jouzel, J., Kaczmarska, M., Karlin, T., Kaufmann, P., Kipfstuhl, S., Kohno, M., Lambert, F., Lambrecht, Anja, Lambrecht, Astrid, Landais, A., Lawer, G., Leuenberger, M., Littot, G., Loulergue, L., Lüthi, D., Maggi, V., Marino, F., MassonDelmotte, V., Meyer, H., Miller, H., Mulvaney, R., Narcisi, B., Oerlemans, J., Oerter, H., Parrenin, F., Petit, J.-R., Raisbeck, G., Raynaud, D., Roethlisberger, R., Ruth, U., Rybak, O., Severi, M., Schmitt, J., Schwander, J., Siegenthaler, U., Siggaard-Andersen, M.-L., Spahni, R., Steffensen, J. P., Stenni, B., Stocker, T. F., Tison, J.-L., Traversi, R., Udisti, R., Valero-Delgado, F., van den Broeke, M. R., van de Wal, R. S. W., Wagenbach, D., Wegner, A., 
Weiler, K., Wilhelms, F., Winther, J.-G., Wolff, E., and EPICA Community Members: One-to-one coupling of glacial climate variability in Greenland and Antarctica, Nature, 444, 195-198, 2006.

Fischer, H., Behrens, M., Bock, M., Richter, U., Schmitt, J., Loulergue, L., Chappellaz, J., Spahni, R., Blunier, T., Leuenberger, M., and Stocker, T. F.: Changing boreal methane sources and constant biomass burning during the last termination, Nature, 452, 864-867, 2008 .

Flückiger, J., Blunier, T., Stauffer, B., Chappellaz, J., Spahni, R., Kawamura, K., Schwander, J., Stocker, T. F., and DahlJensen, D.: $\mathrm{N}_{2} \mathrm{O}$ and $\mathrm{CH}_{4}$ variations during the last glacial epoch: insight into global processes, Global Biogeochem. Сy., 18, GB1020, doi:10.1029/2003GB002122, 2004.

Fung, I., John, J., Lerner, J., Matthews, E., Prather, M., Steele, L., and Fraser, P.: 3-Dimensional model synthesis of the global methane cycle, J. Geophys. Res.-Atmos., 96, 13033-13065, 1991.

Geller, L. S., Elkins, J. W., Lobert, J. M., Clarke, A. D., Hurst, D. F., Butler, J. H., and Myers, R. C.: Troposhperic $\mathrm{SF}_{6}$ : Observed latitudinal distribution and trends, derived emissions and interhemispheric exchange time, Geophys. Res. Lett., 24, 675-678, 1997.

Hein, R., Crutzen, P. J., and Heimann, M.: An inverse modeling approach to investigate the global atmospheric methane cycle, Global Biogeochem. Cy., 11, 43-76, 1997.

Hemming, S. R.: Heinrich events: massive late pleistocene detritus layers of the North Atlantic and their global climate imprint, Rev. Geophys., 42, RG1005, doi:10.1029/2003RG000128, 2004.

Herron, M. M. and Langway, C. C.: Firn densification - an empirical-model, J. Glaciol., 25, 373-385, 1980.

Huber, C., Leuenberger, M., Spahni, R., Flückiger, J., Schwander, J., Stocker, T. F., Johnsen, S., Landais, A., and Jouzel, J.: Isotope calibrated Greenland temperature record over Marine Isotope Stage 3 and its relation to $\mathrm{CH}_{4}$, Earth Planet. Sc. Lett., 243, 504-519, 2006.

Johnsen, S. J., Dahl-Jensen, D., Gundestrup, N., Steffensen, J. P., Clausen, H., Miller, H., Masson-Delmotte, V., Sveinbjornsdottir, A., and White, J.: Oxygen isotope and palaeotemperature records from six Greenland ice-core stations: Camp Century, Dye-3, GRIP, GISP2, Renland and NorthGRIP, J. Quaternary Sci., 16, 299-307, 2001.

Kaplan, J. O., Folberth, G., and Hauglustaine, D. A.: Role of methane and biogenic volatile organic compound sources in late glacial and Holocene fluctuations of atmospheric methane concentrations, Global Biogeochem. Cy., 20, GB2016, doi:10.1029/2005GB002590, 2006.

Lemieux-Dudon, B., Eric, B., Jean-Robert, P., Claire, W., Anders, S., Catherine, R., Jean-Marc, B., Maria, N. B., and Frederic, P.: Consistent dating for Antarctic and Greenland ice cores, Quaternary Sci. Rev., 29, 2821-2822, 2010.

Levine, J. G., Wolff, E. W., Jones, A. E., Sime, L. C., Valdes, P. J., Archibald, A. T., Carver, G. D., Warwick, N. J., and Pyle, J. A.: Reconciling the changes in atmospheric methane sources and sinks between the Last Glacial Maximum and the pre-industrial era, Geophys. Res. Lett., 38, L23804, doi:10.1029/2011GL049545, 2011.

Levine, J. G., Wolff, E. W., Hopcroft, P. O., and Valdes, P. J.: Controls on the tropospheric oxidizing capacity during an idealized Dansgaard-Oeschger event, and their implications for the rapid rises in atmospheric methane during the last glacial period, Geophys. Res. Lett., 39, L12805, doi:10.1029/2012GL051866, 2012.

Mitchell, L. E., Brook, E. J., Sowers, T., McConnell, J. R., and Taylor, K.: Multidecadal variability of atmospheric methane, 1000-1800 C.E., J. Geophys. Res., 116, G02007, doi:10.1029/2010JG001441, 2011.

Andersen, K. K., Azuma, N., Barnola, J. M., Bigler, M., Biscaye, P., Caillon, N., Chappellaz, J., Clausen, H. B., Dahl-Jensen, D., Fischer, H., Fluckiger, J., Fritzsche, D., Fujii, Y., Goto-Azuma, K., Gronvold, K., Gundestrup, N. S., Hansson, M., Huber, C., Hvidberg, C. S., Johnsen, S. J., Jonsell, U., Jouzel, J., Kipfstuhl, S., Landais, A., Leuenberger, M., Lorrain, R., Masson-Delmotte, V., Miller, H., Motoyama, H., Narita, H., Popp, T., Rasmussen, S. O., Raynaud, D., Rothlisberger, R., Ruth, U., Samyn, D., Schwander, J., Shoji, H., Siggard-Andersen, M. L., Steffensen, J. P., Stocker, T., Sveinbjornsdottir, A. E., Svensson, A., Takata, M., Tison, J. L., Thorsteinsson, T., Watanabe, O., Wilhelms, F., and White, J. W. C.: N Greenland Ice Core Project: High-resolution record of Northern Hemisphere climate extending into the last interglacial period, Nature, 431, 147-151, 2004.

Otto-Bliesner, B. L. and Brady, E. C.: The sensitivity of the climate response to the magnitude and location of freshwater forcing: Last Glacial Maximum experiments, Quaternary Sci. Rev., 29, 56-73, 2010.

Quinn, T., Tremaine, S., and Duncan, M.: A 3 million year integration of the Earths orbit, Astron. J., 101, 2287-2305, 1991.

Ruth, U., Barnola, J.-M., Beer, J., Bigler, M., Blunier, T., Castellano, E., Fischer, H., Fundel, F., Huybrechts, P., Kaufmann, P., Kipfstuhl, S., Lambrecht, A., Morganti, A., Oerter, H., Parrenin, F., Rybak, O., Severi, M., Udisti, R., Wilhelms, F., and Wolff, E.: "EDML1": a chronology for the EPICA deep ice core from Dronning Maud Land, Antarctica, over the last 150000 years, Clim. Past, 3, 475-484, doi:10.5194/cp-3-475-2007, 2007.

Schaefer, H. and Whiticar, M. J.: Potential glacial-interglacial changes in stable carbon isotope ratios of methane sources and sink fractionation, Global Biogeochem. Cy., 22, GB1001, doi:10.1029/2006GB002889, 2008.

Schilt, A., Baumgartner, M., Blunier, T., Schwander, J., Spahni, R., Fischer, H., and Stocker, T. F.: Glacial-interglacial and millennial-scale variations in the atmospheric nitrous oxide concentration during the last 800000 years, Quaternary Sci. Rev., 29, 182-192, 2010a.

Schilt, A., Baumgartner, M., Schwander, J., Buiron, D., Capron, E., Chappellaz, J., Loulergue, L., Schüpbach, S., Spahni, R., Fischer, H., and Stocker, T. F.: Atmospheric nitrous oxide during the last 140000 years, Earth Planet. Sc. Lett., 300, 33-43, 2010 b.

Schmidt, M. W. and Spero, H. J.: Meridional shifts in the marine ITCZ and the tropical hydrologic cycle over the last three glacial cycles, Paleoceanography, 26, PA1206, doi:10.1029/2010PA001976, 2011.

Schwander, J., Barnola, J. M., Andrie, C., Leuenberger, M., Ludin, A., Raynaud, D., and Stauffer, B.: The age of the air in the firn and the ice at Summit, Greenland, J. Geophys. Res.-Atmos., 98, 2831-2838, 1993.

Singarayer, J. S., Valdes, P. J., Friedlingstein, P., Nelson, S., and Beerling, D. J.: Late Holocene methane rise caused by orbitally controlled increase in tropical sources, Nature, 470, 82-85, 2011.

Sowers, T.: Atmospheric methane isotope records covering the Holocene period, Quaternary Sci. Rev., 29, 213-221, 2010. 
Spahni, R., Schwander, J., Flückiger, J., Stauffer, B., Chappellaz, J., and Raynaud, D.: The attenuation of fast atmospheric $\mathrm{CH}_{4}$ variations recorded in polar ice cores, Geophys. Res. Lett., 30, 1571, doi:10.1029/2003GL017093, 2003.

Spahni, R., Chappellaz, J., Stocker, T. F., Loulergue, L., Hausammann, G., Kawamura, K., Flückiger, J., Schwander, J., Raynaud, D., Masson-Delmotte, V., and Jouzel, J: Atmospheric Methane and Nitrous Oxide of the Late Pleistocene from Antarctic Ice Cores, Science, 310, 1317-1321, 2005.

Spahni, R., Wania, R., Neef, L., van Weele, M., Pison, I., Bousquet, P., Frankenberg, C., Foster, P. N., Joos, F., Prentice, I. C., and van Velthoven, P.: Constraining global methane emissions and uptake by ecosystems, Biogeosciences, 8, 1643-1665, doi:10.5194/bg8-1643-2011, 2011.

Stager, J. C., Ryves, D. B., Chase, B. M., and Pausata, F. S. R.: Catastrophic drought in the Afro-Asian monsoon region during Heinrich Event 1, Science, 331, 1299-1302, 2011.

Steele, L., Dlugokencky, E., Lang, P., Tans, P., Martin, R., and Masarie, K.: Slowing down of the global accumulation of atmospheric methane during the 1980s, Nature, 358, 313-316, 1992.

Stenni, B., Buiron, D., Frezzotti, M., Albani, S., Barbante, C., Bard, E., Barnola, J. M., Baroni, M., Baumgartner, M., Bonazza, M., Capron, E., Castellano, E., Chappellaz, J., Delmonte, B., Falourd, S., Genoni, L., Iacumin, P., Jouzel, J., Kipfstuhl, S., Landais, A., Lemieux-Dudon, B., Maggi, V., Masson-
Delmotte, V., Mazzola, C., Minster, B., Montagnat, M., Mulvaney, R., Narcisi, B., Oerter, H., Parrenin, F., Petit, J. R., Ritz, C., Scarchilli, C., Schilt, A., Schüpbach, S., Schwander, J., Selmo, E., Severi, M., Stocker, T. F., and Udisti, R.: Expression of the bipolar see-saw in Antarctic climate records during the last deglaciation, Nat. Geosci., 4, 46-49, 2011.

Stocker, T. F. and Johnsen, S. J.: A minimum thermodynamic model for the bipolar seesaw, Paleoceanography, 18, 920, doi:10.1029/2003PA000920, 2003.

Tans, P.: A note on isotopic ratios and the global atmospheric methane budget, Global Biogeochem. Cy., 11, 77-81, 1997.

Wang, Y. J., Cheng, H., Edwards, R. L., An, Z. S., Wu, J. Y., Shen, C. C., and Dorale, J. A.: A high-resolution absolute-dated Late Pleistocene monsoon record from Hulu Cave, China, Science, 294, 2345-2348, 2001.

Wang, X., Auler, A. S., Edwards, R. L., Cheng, H., Ito, E., Wang, Y., Kong, X., and Solheid, M.: Millennial-scale precipitation changes in southern Brazil over the past 90000 years, Geophys. Res. Lett., 34, L23701, doi:10.1029/2007GL031149, 2007.

Weber, S. L., Drury, A. J., Toonen, W. H. J., and van Weele, M.: Wetland methane emissions during the Last Glacial Maximum estimated from PMIP2 simulations: climate, vegetation, and geographic controls, J. Geophys. Res.-Atmos., 115, D06111, doi:10.1029/2009JD012110, 2010. 